\title{
Article \\ Clustering Inflammatory Markers with Sociodemographic and Clinical Characteristics of Patients with Diabetes Type 2 Can Support Family Physicians' Clinical Reasoning by Reducing Patients' Complexity
}

\author{
Zvonimir Bosnic ${ }^{1} \oplus$, Pinar Yildirim ${ }^{2}$, František Babič ${ }^{3}$, Ines Šahinović ${ }^{4}$, Thomas Wittlinger ${ }^{5}$, Ivo Martinović 6,7 \\ and Ljiljana Trtica Majnaric ${ }^{1, *(D)}$ \\ Citation: Bosnic, Z.; Yildirim, P.; \\ 1 Department of Internal Medicine, Family Medicine and the History of Medicine, Faculty of Medicine, \\ Josip Juraj Strossmayer University of Osijek, 31000 Osijek, Croatia; zbosnic191@gmail.com \\ 2 Department of Computer Engineering, Faculty of Engineering and Natural Science, Istanbul Okan University, \\ 34959 Istanbul, Turkey; pinar.yildirim@okan.edu.tr \\ 3 Department of Cybernetics and Artificial Intelligence, Faculty of Electrical Engineering and Informatics, \\ Technical University of Košice, 04201 Košice, Slovakia; frantisek.babic@tuke.sk \\ 4 Department of Clinical Laboratory Diagnostics, Osijek University Hospital Centre, 31000 Osijek, Croatia; \\ ines.sahinovic@kbco.hr \\ 5 Department of Cardiology, Asklepios Hospital, 38642 Goslar, Germany; dr.wittlinger@gmx.de \\ 6 Department of Cardiothoracic Surgery, University Hospital Marburg, 35033 Marburg, Germany; \\ ivo.martinovic@med.uni-marburg.de \\ 7 Faculty of Dental Medicine and Health Osijek, J.J. Strossmayer University of Osijek, 31000 Osijek, Croatia \\ * Correspondence: ljiljana.majnaric@mefos.hr
} Babič, F.; Šahinović, I.; Wittlinger, T.; Martinović, I.; Majnaric, L.T. Clustering Inflammatory Markers with Sociodemographic and Clinical Characteristics of Patients with Diabetes Type 2 Can Support Family Physicians' Clinical Reasoning by Reducing Patients' Complexity. Healthcare 2021, 9, 1687. https:// doi.org/10.3390/healthcare9121687

Academic Editor: Christiano Argano

Received: 26 October 2021

Accepted: 2 December 2021

Published: 6 December 2021

Publisher's Note: MDPI stays neutral with regard to jurisdictional claims in published maps and institutional affiliations.

Copyright: (C) 2021 by the authors. Licensee MDPI, Basel, Switzerland. This article is an open access article distributed under the terms and conditions of the Creative Commons Attribution (CC BY) license (https:/ / creativecommons.org/licenses/by/ $4.0 /)$.
Abstract: Diabetes mellitus type 2 (DM2) is a complex disease associated with chronic inflammation, end-organ damage, and multiple comorbidities. Initiatives are emerging for a more personalized approach in managing DM2 patients. We hypothesized that by clustering inflammatory markers with variables indicating the sociodemographic and clinical contexts of patients with DM2, we could gain insights into the hidden phenotypes and the underlying pathophysiological backgrounds thereof. We applied the k-means algorithm and a total of 30 variables in a group of 174 primary care (PC) patients with DM2 aged 50 years and above and of both genders. We included some emerging markers of inflammation, specifically, neutrophil-to-lymphocyte ratio (NLR) and the cytokines IL-17A and IL-37. Multiple regression models were used to assess associations of inflammatory markers with other variables. Overall, we observed that the cytokines were more variable than the marker NLR. The set of inflammatory markers was needed to indicate the capacity of patients in the clusters for inflammatory cell recruitment from the circulation to the tissues, and subsequently for the progression of end-organ damage and vascular complications. The hypothalamus-pituitary-thyroid hormonal axis, in addition to the cytokine IL-37, may have a suppressive, inflammation-regulatory role. These results can help PC physicians with their clinical reasoning by reducing the complexity of diabetic patients.

Keywords: diabetes type 2; chronic inflammation; complex chronic diseases; primary care patients; phenotyping; data mining; clustering techniques

\section{Background}

Chronic inflammation is considered the main mechanism in aging and the development of chronic diseases, including diabetes mellitus type 2 (DM2), cardiovascular disease (CVD), neurodegenerative disease, and some malignant and musculoskeletal diseases [1]. It has been recognized that the impact of environmental factors is more important than genetics in directing the course of aging towards "unsuccessful aging", that is, aging burdened with chronic diseases and functional impairments [2,3]. There are numerous sources of inflammation in older individuals, with cell senescence and chronic activation 
of the innate immune receptors being the main ones [3]. Changes in the body's shape and structure that occur with aging, including muscle loss and an increase in visceral fat, significantly contribute to inflammation and the development of insulin resistance, which taken together increase the risk for metabolic and vascular disorders [4]. Obesity accelerates these age-related processes [4]. It has become increasingly clear that age-related inflammation is a whole-body response, which involves a variety of brain-immune and gut-brain feedback loops [2]. Many compensatory and anti-inflammatory mechanisms, still insufficiently known, may counteract the deleterious effects of chronic inflammation on survival and functional decline of older individuals $[1,5]$.

DM2 is a complex chronic disease that involves metabolic, inflammatory, and vascular disorders [6]. Because of its global spread and serious consequences, DM2 represents a major public health concern [7]. Notably, the risk of CVD as a leading cause of mortality is several times higher in these patients than in the general population $[8,9]$. Initiatives are emerging for a more personalized approach in managing patients with DM2 [10]. In addition, efforts have been undertaken to develop new treatment strategies. Instead of focusing on antihyperglycemic treatment effects, as was the case in old-fashioned medications, the focus now is on CV benefits that go beyond glucose-lowering effects [11].

For risk stratification and customized treatment of diabetic patients, it is important to know that CVD, DM2, and comorbidities such as hypertension, metabolic syndrome (a cluster of disorders associated with visceral obesity), and chronic kidney disease (CKD) have a common pathophysiological background $[4,12,13]$. Moreover, because of the current understanding of inflammation as the common driver of age-related chronic diseases, other comorbidities that cluster together with DM2 and CVD should be taken into consideration as well [14]. This is also the case for mental disorders, anxiety, and depression, which are known to often accompany DM2 and CVD, worsening the course of these conditions [15]. Recent evidence indicates that frailty, if associated with chronic health conditions, can modify CV risk factors and influence the outcomes [16-18]. The state of frailty is manifested by a reduction in muscle mass and strength, slow walking, and low activity and is considered reflective of exhausted homeostatic reserves in multiple organs and systems [19].

Inflammatory markers such as the cytokine IL- 6 and the acute-phase reactant Creactive protein (CRP) have long been used to stratify risk in patients with $C V$ risk factors [20]. Recently, however, a more prevalent role has been given to the neutrophil-tolymphocyte ratio (NLR) [21]. NLR represents a low-cost and widely available laboratory parameter and is suitable for community-based research. In addition, it reflects tissuerelated inflammatory processes associated with the progression of atherosclerosis and end-organ damage [22-25]. In both cases, increased recruitment of inflammatory and immune cells from the circulation to the tissue via dysfunctional vascular endothelial cells constitutes the main underlying mechanism [26,27]. Distinctly from atherosclerosis, in which large arteries are the target of an inflammatory response, microcirculation plays a major role in tissue-related cell infiltration, which occurs during the progression of end-organ damage. However, before NLR can be used routinely, it needs to be validated in different populations, as many sociodemographic and lifestyle factors can influence variations in its values [28]. The relevant reference values need to be identified not only for the general population, but also to distinguish between particular cohorts or to indicate specific adverse outcomes [29].

Some new markers of inflammation have been explored for their potential use for risk stratification in everyday clinical practice. A very promising one is the proinflammatory cytokine IL-17A [30]. For its effect on mobilization of inflammatory cells from the circulation to the tissues, particularly relating to neutrophils and Th17 lymphocytes, the main effector cells in tissue-related chronic inflammation, this cytokine plays a central role in the process of end-organ damage and is complementary to NLR [31]. The role of this cytokine in promoting diabetic CKD has been clearly confirmed in experimental studies [32]. Another promising inflammatory marker, yet unexplored in real-life settings, is cytokine IL-37, which has been recognized for its broad anti-inflammatory and glucose 
homeostasis modulating effects $[33,34]$. This cytokine was found to be directly involved in reducing high-glucose-induced inflammation and oxidative stress as well as organ damage caused by these mechanisms [35]. Both cytokines proposed in this study have a chance to be used as new biological treatments. If this happens, it will constitute a major turn in medication therapy that can be used for preventing CVD in patients with DM2 [36]. Moreover, the possibility to detect gene polymorphisms for these cytokines may prompt personalized treatment strategies [37].

\section{Aim}

Currently, there is no consensus as to which markers of inflammation best represent chronic inflammation or can distinguish among the various phases of inflammatory responses [38]. The fact that DM2 is mostly an age-related disease accentuates heterogeneity of DM2-related phenotypes by increasing the potential in DM2 patients for the development of multiple comorbidities, malnutrition, sarcopenia, and frailty $[39,40]$. In addition to the well-known fact that the risk of vascular complications and mortality increases with the duration of DM2 and is dependent on how glycemia is regulated, new evidence has also emphasized, in this regard, the importance of patient age and the age of DM2 onset $[9,41]$. Guided by these facts, we hypothesized that by clustering inflammatory markers with variables indicating sociodemographic and clinical characteristics of patients with DM2, we could gain insights into the hidden phenotypic subtypes that exist in primary care (PC) diabetic patients in a real-life setting and in inflammation-related pathophysiology networks that stay beyond these phenotypes. The proposed research approach was expected to help PC physicians with clinical reasoning by reducing the diagnostic uncertainty that PC physicians deal with on a daily basis when facing complexity of patients with DM2 and other chronic age-related diseases [42].

\section{Methods}

\subsection{Study Population}

The study was performed in a PC setting in the area of Slavonski Brod $(59,000$ residents), a town in the southeastern part of Croatia. In Croatia, family physicians have a gatekeeping role, which enables good access to the general population. PC services are supported by an IT system [43]. Chronic disease surveillance and preventive check-up platforms were established as a part of electronic health records (eHRs) to improve screening and management strategies for patients with some important chronic conditions, including DM2. Despite the established eHRs, patient data are still extracted manually, however, as eHRs in individual family medicine (FM) practices are not integrated into the common research platform. Our study patients were recruited from four FM practices in which family physicians allowed access to medical records. The study was approved by the Expert and Ethics Council of the Health Center of Slavonski Brod (ID:1433-1/020).

Patients aged 50 years and above of both genders and diagnosed with DM2 were recruited into the study. At these ages, obesity, metabolic disorders, and DM2 also start to emerge at higher rates [44]. In the FM practices included in the study, 1600-1800 patients were registered in the lists, giving a source population of 6500-7000. About a quarter of patients (400-450 patients per one FM practice) were from the target age groups. The number of patients per FM practice who were diagnosed with DM2 amounted to 80-100, with the prevalent number being from the target age groups.

As selection criteria, patients had to be able to independently visit their family physicians and give written informed consent. Patients with acute conditions or in rapidly declining health and those with malignant diseases who had received chemo- or radiotherapy or biological treatments were excluded. Also excluded were individuals with an amputated leg, those on continuous renal replacement therapy or with a transplanted kidney, and those with dementia or significant cognitive dysfunction.

The study was conducted over a period of four months, from September to December 2020. Of the initially selected 228 eligible patients, 190 patients finished the study protocol. 
During the study period, the first COVID-19 pandemic wave was underway, and mass vaccination had not yet been introduced, which hindered study execution. We were also limited by the package size of the cytokine research reagents, so the final number of patients for whom a full set of data was available, as planned for research, was 174 .

\subsection{Data Collection}

We used a total of 30 variables, of which 4 were markers of inflammation and all of the others were patient sociodemographic and health status characteristics (Table 1).

Table 1. The variable description for 30 variables included in the study.

\begin{tabular}{|c|c|c|c|}
\hline No & Variables and Their Abbreviations & \multicolumn{2}{|c|}{ Variable Description } \\
\hline 1 & Gender & \multicolumn{2}{|c|}{$\begin{array}{c}\text { Categorical }(0,1) \\
\text { Category frequency } \\
\text { Males }=98 \\
\text { Females }=76\end{array}$} \\
\hline 2 & Age (years) & \multicolumn{2}{|c|}{$\begin{array}{c}\text { Numerical } \\
\text { Mean: } 67.03 \\
\text { Max }=88, \text { Min }=50\end{array}$} \\
\hline 3 & Number of comorbidities $(<3, \geq 3)$ & \multicolumn{2}{|c|}{$\begin{array}{c}\text { Categorical }(0,1) \\
\text { Category frequency } \\
0=8 \\
1=166\end{array}$} \\
\hline 4 & $\begin{array}{l}\text { Body mass index }(\mathrm{BMI}) \\
\qquad\left(\mathrm{kg} / \mathrm{m}^{2}\right)\end{array}$ & \multicolumn{2}{|c|}{$\begin{array}{c}\text { Numerical } \\
\text { Mean: } 30.53 \\
\text { Max }=51.37, \operatorname{Min}=19.4\end{array}$} \\
\hline 5 & $\begin{array}{l}\text { Midarm circumference (mac) } \\
\qquad(\mathrm{cm})\end{array}$ & \multicolumn{2}{|c|}{$\begin{array}{c}\text { Numerical } \\
\text { Mean: } 29.974 \\
\operatorname{Max}=39, \operatorname{Min}=21\end{array}$} \\
\hline 6 & $\begin{array}{c}\text { Marker of inflammation-related anemia } \\
\text { Hemoglobin }(\mathrm{Hb}) \\
(\mathrm{g} / \mathrm{L})\end{array}$ & \multicolumn{2}{|c|}{$\begin{array}{c}\text { Numerical } \\
\text { Mean: } 142.27 \\
\text { Max }=166, \text { Min }=93\end{array}$} \\
\hline 7 & $\begin{array}{l}\text { Estimated glomerular filtration rate (eGFR) } \\
\qquad\left(\mathrm{mL} / \mathrm{min} / 1.73 \mathrm{~m}^{2}\right)\end{array}$ & \multicolumn{2}{|c|}{$\begin{array}{c}\text { Numerical } \\
\text { Mean: } 80.723 \\
\operatorname{Max}=163, \operatorname{Min}=29\end{array}$} \\
\hline \multirow{6}{*}{8} & \multirow{6}{*}{ eGFR levels } & \multicolumn{2}{|c|}{$\begin{array}{c}\text { Nominal } \\
1,2,3,4\end{array}$} \\
\hline & & Category & Frequency \\
\hline & & 1 & 55 \\
\hline & & 2 & 64 \\
\hline & & 3 & 43 \\
\hline & & 4 & 12 \\
\hline 9 & $\begin{array}{l}\text { Triglycerides } \\
(\mathrm{mmol} / \mathrm{L})\end{array}$ & $\mathrm{N}$ & \\
\hline 10 & $\begin{array}{l}\text { HDL cholesterol } \\
\qquad(\mathrm{mmol} / \mathrm{L})\end{array}$ & $\mathrm{M}$ & \\
\hline 11 & $\begin{array}{l}\text { Thyroid-stimulating hormone (TSH) } \\
\qquad(\mathrm{mU} / \mathrm{L})\end{array}$ & & \\
\hline
\end{tabular}


Table 1. Cont.

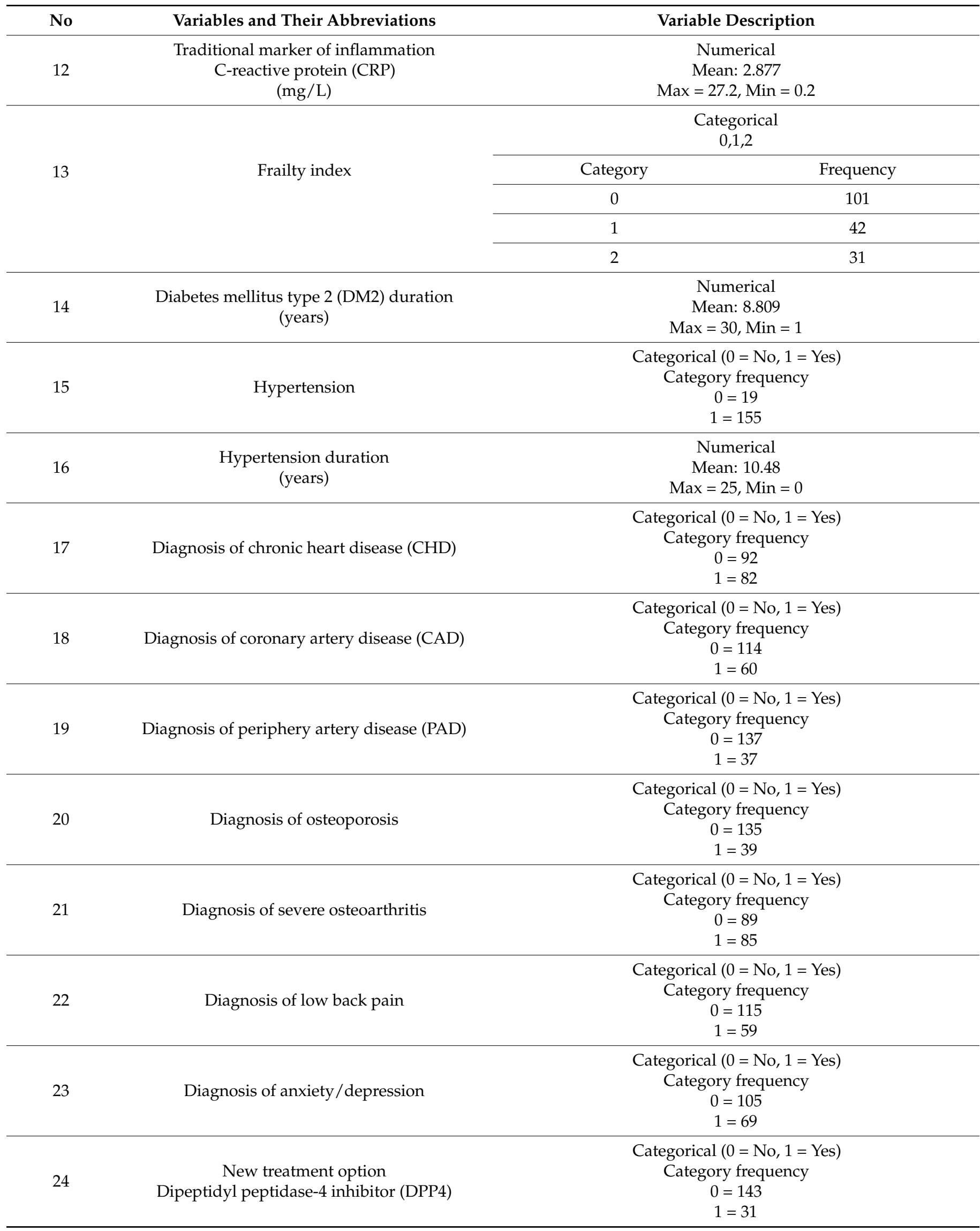


Table 1. Cont.

\begin{tabular}{|c|c|c|}
\hline No & Variables and Their Abbreviations & Variable Description \\
\hline 25 & $\begin{array}{l}\text { New treatment option } \\
\text { Sodium glucose cotransporter-2 inhibitors } \\
\text { (SGLT2) }\end{array}$ & $\begin{array}{l}\text { Categorical }(0=\mathrm{No}, 1=\text { Yes }) \\
\begin{array}{c}\text { Category frequency } \\
0=167 \\
1=7\end{array}\end{array}$ \\
\hline 26 & $\begin{array}{l}\text { New treatment option } \\
\text { Glucagon-likepeptide-1 receptor agonists } \\
\text { (GLP1r) }\end{array}$ & $\begin{array}{l}\text { Categorical }(0=\mathrm{No}, 1=\text { Yes }) \\
\begin{array}{c}\text { Category frequency } \\
0=158 \\
1=16\end{array}\end{array}$ \\
\hline 27 & Therapy with insulin & $\begin{array}{l}\text { Categorical }(0=\mathrm{No}, 1=\text { Yes }) \\
\begin{array}{c}\text { Category frequency } \\
0=134 \\
1=40\end{array}\end{array}$ \\
\hline 28 & $\begin{array}{l}\text { Emerging marker of inflammation } \\
\text { Neutrophil-to-lymphocyte ratio (NLR) }\end{array}$ & $\begin{array}{c}\text { Numerical } \\
\text { Mean: } 1.718 \\
\operatorname{Max}=5.4, \operatorname{Min}=0.6\end{array}$ \\
\hline 29 & $\begin{array}{c}\text { Emerging marker of inflammation } \\
\text { Il-17A } \\
(\mathrm{pg} / \mathrm{mL})\end{array}$ & $\begin{array}{c}\text { Numerical } \\
\text { Mean: } 3.291 \\
\text { Max }=75.52 \\
\text { Min }=0.01\end{array}$ \\
\hline 30 & $\begin{array}{l}\text { Emerging marker of inflammation } \\
\text { Il-37 } \\
(\mathrm{pg} / \mathrm{mL})\end{array}$ & $\begin{array}{c}\text { Numerical } \\
\text { Mean: } 42.679 \\
\text { Max }=1788.4 \\
\text { Min }=0.14\end{array}$ \\
\hline
\end{tabular}

Two markers of inflammation are routinely used in the PC setting, CRP and hemoglobin $(\mathrm{Hb})$, a marker of anemia of inflammation and chronic diseases [45]. We also included some emerging markers of inflammation in the study; we propose that NLR and the cytokine IL-17A better reflect tissue-related chronic inflammation and that cytokine IL-37 indicates the anti-inflammatory response.

Blood samples were taken from patients for laboratory testing. All tests were performed in the local hospital's central laboratory, except the analysis of cytokines, for which blood specimens were sent to the laboratory for molecular immunology of the University Hospital Clinical Center in Osijek, the administrative and university center of this region. Serum lipids, triglycerides, and HDL cholesterol were included in the dataset, as they indicate metabolic syndrome, a metabolic disorder associated with obesity, hypertension, and DM2 [9]. We did not include LDL cholesterol, as many patients were treated with hypolipidemic drugs, and serum concentrations of this lipid fraction were significantly modified by this treatment. We needed serum creatinine tests to estimate the glomerular filtration rate (eGFR), a measure of renal function decline [46]. According to the international classification, there are 4 levels of renal function decline, where levels 1 and 2 are associated with preserved function and levels 3 and 4 with lowered function. This measure was calculated using an online calculator [47]. Variations in TSH values can reveal age-related dysregulation of the hypothalamus-pituitary-thyroid axis, which is known to be implicated in metabolic and CV disorders in older individuals, in particular those with multiple comorbidities [48]. TSH levels in the range of 4-10 mU/L indicate latent hypothyroidism, a common age-related disorder, but still not in need of treatment. The NLR was calculated from the complete blood count with differential [49].

From eHRs, we used data indicating patient sociodemographic characteristics, comorbidities, and treatment options for DM2. We took into consideration only comorbidities known to be closely associated with DM2, such as hypertension and CVD, and which frequently affect diabetic patients or significantly contribute to inflammation, such as the common musculoskeletal disorders and anxiety/depression [50]. Of currently available 
treatment options for DM2, we included insulin therapy for its known anti-inflammatory effect and new antidiabetic medications for their favorable CV effects [51,52].

Anthropometric measurements of body mass index (BMI), indicating general obesity, and midarm circumference (mac), indicating muscle loss, were performed in patients at their visits [53]. Patients were also assessed for physical frailty using Fried's phenotype model [19]. This model takes into account five predefined and easily measured criteria, weight loss, feeling of exhaustion, low physical activity, slow walking, and weakness (low grip strength, measured by hand dynamometer). Patients were classified by the number of positive criteria as being frail ( $\geq 3)$, prefrail (1-2), or robust (none).

Although medical science is disease based, there is no adequate way to integrate the coexisting diseases in complex patients [54]. For creating clusters, we used the item "the number of comorbidities" (<3 vs. $\geq 3$ ) rather than CIRS (the Cumulative Illness Rating Scale), today the most used weighted scoring system for measuring comorbidity-related complexity [55]. This instrument comprehensively evaluates impairments in different organs and systems, depending on their levels of severity, but without using specific diagnoses of diseases. In this study, there was no need to comprehensively assess all possible comorbidities that a patient had. Instead of that, the aim was to explore the most common comorbidities of patients with DM2 that are, at the same time, associated with increased inflammation. In doing so, we relied on both, evidence indicating CVD as the most prevalent comorbidities in patients diagnosed with DM2 and information indicating the most common non-CV comorbidities that can be found in patients with DM2 in our surrounding area [50].

In addition, CIRS was validated for some specifically defined outcomes, such as hospital-related mortality and the length of hospital stay [55]. This study had a crosssectional design and the aim to find out the reasonable phenotypic patterns of patients with DM2 that may be hidden within the dataset.

Moreover, although CIRS takes into account a contribution of each organ impairment to the comorbidity burden, it cannot discern among particular conditions, as it uses aggregate measures of the employed items [55]. A simple count of comorbidities, on the contrary, does not account on the severity of particular disease. This was, in our study, to some extent compensated by the involvement of some other clinical variables, such as laboratory tests, anthropometric measures, and frailty status, which helped us stratify patients into clusters according to levels of severity.

Furthermore, CIRS is based on the assumption that diseases and impairments do not associate with each other, while it is known that disease clustering (nonrandom associations) and disease interactions are features inherent to multimorbidity and complexity [56]. Imbalanced distribution of particular comorbid conditions among the clusters, in this study, revealed the nonrandom associations of these conditions with each other and with other features that were used to create the clusters, of which some contained prognostic elements (for, e.g., DM2 duration and the time of onset) [56,57]. In this way, the applied research approach incorporated many aspects of the concept of complex patients, such as different types of features interacting with each other, staging of severity, treatment difficulties, nonlinear associations (a small difference in one variable leading to a large difference in another variable), and feature patterns being inherently associated with phenotypes, which to some extent have a prognostic capacity [54,57].

\subsection{Statistical Analysis}

Numerical variables were presented as a range (min-max) and the arithmetic mean. Categorical variables were presented as frequencies of predefined categories (Table 1). The k-means algorithm, a machine-learning method, was applied to the dataset to search for hidden clusters [58]. In addition, we used multivariate linear regression (MLR) models to assess the statistically significant correlations between the variables NLR, Il-17A, and Il-37, indicating chronic inflammation (used as dependent variables), and all other variables, indicating patient contexts (used as independent variables). Statistical analyses were 
performed using WEKA 3.9.5 software, an open-source software consisting of machinelearning algorithms for data-mining tasks. It contains some tools for data preprocessing, classification, regression, clustering, and association-rules mining [59].

\subsection{Cluster Analysis}

Cluster analysis constitutes one of the main methods for data-mining studies [60]. The process of separating many objects into classes is known as clustering. A cluster is a collection of data that are similar or close to each other and far from data in other clusters. Cluster analysis is widely used in a variety of applications, including pattern recognition, data analysis, image processing, and biomedical research.

There are different clustering methods [61]. In this study, we used the k-means algorithm, a simple and effective method for implementation [62]. It is one of the socalled unsupervised learning methods, which means that knowledge of the outcome is not specified in advance. Such methods are used when undefined patterns or clusters need to be found in a dataset or to reduce the number of variables.

The k-means algorithm requires that the number of clusters $(\mathrm{k})$ in the data is prespecified [63]. Finding the appropriate number of clusters for a given dataset is often difficult, and it takes many trials to decide which clustering option is "correct". There is a relationship between performing the algorithm and choosing the k-value. However, studies on k-means clustering do not give much information on how to choose the k-value [64]. Implementation of the k-means algorithm in some software packages and tools requires the number of clusters to be specified by the user. To achieve high accuracy for the model, the algorithm must be run with many k-values and the results observed.

\subsection{Data Analysis Procedure}

We applied the $k$-means algorithm for different numbers of clusters $(3 \leq k \geq 6)$ and observed the results of the sum of squared errors and run time for both clustering studies. The total squared error (SSE) shows how similar data in a set are to each other [63]. We compared the results of different numbers of clusters generated and found that the error decreased as the number of clusters increased. For example, when the value of $\mathrm{k}$ was 3 , the SSE was 2712, and when the value of $k$ increased to 6, the new value of the SSE was 2592 (Table 2).

Table 2. Cluster analysis evaluation.

\begin{tabular}{ccc}
\hline K Value & Number of Iterations & Within-Cluster Sum of Squared Errors \\
\hline 3 & 8 & 2712 \\
\hline 4 & 7 & 2689 \\
\hline 5 & 8 & 2593 \\
\hline 6 & 7 & 2592 \\
\hline
\end{tabular}

We obtained two results based on 3 and 6 clusters (Tables 3 and 4). 
Table 3. Clusters obtained by k-means algorithm with $\mathrm{k}=3$. The 3-cluster model.

\begin{tabular}{|c|c|c|c|}
\hline Variable & $\mathrm{Cl} \mathrm{1/3}$ & $\mathrm{Cl} 2 / 3$ & $\mathrm{Cl} 3 / 3$ \\
\hline Gender $(\mathrm{M}, \mathrm{F})(0,1)$ & 1 & 0 & 1 \\
\hline Age (years) & 61 & 63 & 72 \\
\hline $\begin{array}{l}\text { Number of comorbidities } \\
\qquad(<3, \geq 3)(0,1)\end{array}$ & 1 & 1 & 1 \\
\hline $\operatorname{BMI}\left(\mathrm{kg} / \mathrm{m}^{2}\right)$ & 37 & 32 & 27 \\
\hline $\operatorname{mac}(\mathrm{cm})$ & 29 & 30 & 28 \\
\hline $\mathrm{Hb}(\mathrm{g} / \mathrm{L})$ & 148 & 142 & 123 \\
\hline eGFR $\left(\mathrm{mL} / \mathrm{min} / 1.73 \mathrm{~m}^{2}\right)$ & 82 & 59 & 29 \\
\hline eGFR levels (1-4) & 2 & 1 & 3 \\
\hline Triglycerides (mmol/L) & 1.5 & 1.6 & 2.1 \\
\hline HDL cholesterol (mmol/L) & 1.4 & 1.3 & 1.2 \\
\hline TSH (mU/L) & 3.3 & 2.2 & 1.2 \\
\hline CRP (mg/L) & 1.2 & 1.1 & 0.8 \\
\hline Frailty index $(0,1,2)$ & 0 & 0 & 2 \\
\hline $\begin{array}{l}\text { DM2 duration } \\
\quad \text { (years) }\end{array}$ & 1 & 2 & 10 \\
\hline $\begin{array}{c}\text { Hypertension } \\
(0=\text { No, } 1 \text { = Yes })\end{array}$ & 1 & 1 & 1 \\
\hline $\begin{array}{l}\text { Hypertension duration } \\
\text { (years) }\end{array}$ & 10 & 0 & 15 \\
\hline CHD $(0=$ No, $1=$ Yes $)$ & 1 & 0 & 1 \\
\hline $\mathrm{CAD}(0=\mathrm{No}, 1=\mathrm{Yes})$ & 0 & 0 & 1 \\
\hline $\operatorname{PAD}(0=$ No, $1=$ Yes $)$ & 0 & 0 & 1 \\
\hline $\begin{array}{c}\text { Osteoporosis } \\
(0=\mathrm{No}, 1=\mathrm{Yes})\end{array}$ & 0 & 0 & 0 \\
\hline $\begin{array}{l}\text { Severe osteoarthritis } \\
\quad(0=\mathrm{No}, 1=\text { Yes })\end{array}$ & 1 & 0 & 1 \\
\hline $\begin{array}{l}\text { Low back pain } \\
(0=\text { No, } 1=\text { Yes })\end{array}$ & 1 & 0 & 1 \\
\hline $\begin{array}{l}\text { Anxiety/depression } \\
(0=\text { No, } 1=\text { Yes })\end{array}$ & 1 & 0 & 1 \\
\hline $\begin{array}{l}\text { DPP4 therapy } \\
(0=\text { No, } 1=\text { Yes })\end{array}$ & 0 & 0 & 0 \\
\hline $\begin{array}{l}\text { SGLT2 therapy } \\
(0=\mathrm{No}, 1=\text { Yes })\end{array}$ & 0 & 0 & 0 \\
\hline $\begin{array}{l}\text { GLP1r therapy } \\
(0=\mathrm{No}, 1=\text { Yes })\end{array}$ & 0 & 0 & 0 \\
\hline $\begin{array}{l}\text { Insulin therapy } \\
(0=\mathrm{No}, 1=\text { Yes })\end{array}$ & 0 & 0 & 0 \\
\hline NLR & 1.1 & 1.7 & 1.7 \\
\hline Il-17A (pg/mL) & 0.68 & 1.42 & 0.68 \\
\hline Il-37 (pg/mL) & 0.24 & 0.8 & 13.4 \\
\hline
\end{tabular}

Cl-Cluster; BMI—body mass index; mac-midarm circumference; $\mathrm{Hb}$-hemoglobin; NLR—neutrophil-tolymphocyte ratio; eGFR - estimated glomerular filtration rate; TSH—thyroid-stimulating hormone; CRP-Creactive protein; $\mathrm{DM} 2$ - diabetes mellitus type 2; CHD—chronic heart disease; $\mathrm{CAD}$-coronary artery disease; PAD—peripheral artery disease; DPP4—dipeptidyl peptidase-4 inhibitor; SGLT2—sodium-glucose cotransporter2 inhibitors; GLP1r—glucagon-like peptide-1 receptor agonists. 
Table 4. Clusters obtained by $\mathrm{k}$-means algorithm with $\mathrm{k}=6$. The six-cluster model

\begin{tabular}{|c|c|c|c|c|c|c|}
\hline Variable & Cl 1/6 & $\mathrm{Cl} \mathrm{2/6}$ & $\mathrm{Cl} \mathrm{3/6}$ & $\mathrm{Cl} 4 / 6$ & $\mathrm{Cl} \mathrm{5/6}$ & $\mathrm{Cl} \mathrm{6/6}$ \\
\hline Gender $(\mathrm{M}, \mathrm{F})(0,1)$ & 0 & 1 & 0 & 1 & 0 & 0 \\
\hline Age (years) & 61 & 64 & 72 & 80 & 67 & 61 \\
\hline Number of comorbidities $(<3, \geq 3)(0,1)$ & 1 & 1 & 1 & 1 & 1 & 1 \\
\hline BMI $\left(\mathrm{kg} / \mathrm{m}^{2}\right)$ & 32 & 31.64 & 28.4 & 24.03 & 26 & 26.78 \\
\hline $\operatorname{mac}(\mathrm{cm})$ & 32 & 30 & 33 & 27 & 29 & 28 \\
\hline $\mathrm{Hb}(\mathrm{g} / \mathrm{L})$ & 157 & 142 & 123 & 134 & 129 & 162 \\
\hline $\mathrm{eGFR}\left(\mathrm{mL} / \mathrm{min} / 1.73 \mathrm{~m}^{2}\right)$ & 79 & 87 & 29 & 59 & 59 & 58 \\
\hline eGFR levels (1-4) & 1 & 2 & 3 & 3 & 2 & 1 \\
\hline Triglycerides (mmol/L) & 1.5 & 1.2 & 1.2 & 1.9 & 2.1 & 1 \\
\hline HDL cholesterol (mmol/L) & 1.3 & 1.2 & 1.2 & 1.2 & 1.5 & 1.6 \\
\hline $\mathrm{TSH}(\mathrm{mU} / \mathrm{L})$ & 2.1 & 2.2 & 2.39 & 3.3 & 1.9 & 2.2 \\
\hline $\mathrm{CRP}(\mathrm{mg} / \mathrm{L})$ & 1.1 & 0.9 & 0.6 & 0.8 & 1.1 & 1.2 \\
\hline Frailty index $(0,1,2)$ & 0 & 0 & 0 & 2 & 0 & 0 \\
\hline DM2 duration (years) & 10 & 2 & 1 & 12 & 3 & 2 \\
\hline $\begin{array}{c}\text { Hypertension } \\
(0=\text { No, } 1=\text { Yes })\end{array}$ & 1 & 1 & 1 & 1 & 1 & 0 \\
\hline $\begin{array}{l}\text { Hypertension duration } \\
\text { (years) }\end{array}$ & 10 & 7 & 10 & 15 & 15 & 0 \\
\hline CHD $(0=$ No, $1=$ Yes $)$ & 0 & 0 & 1 & 1 & 0 & 0 \\
\hline CAD $(0=$ No, $1=$ Yes $)$ & 0 & 0 & 1 & 1 & 0 & 0 \\
\hline $\operatorname{PAD}(0=$ No, $1=$ Yes $)$ & 0 & 0 & 1 & 1 & 0 & 0 \\
\hline $\begin{array}{c}\text { Osteoporosis } \\
(0=\text { No, } 1=\text { Yes })\end{array}$ & 0 & 0 & 0 & 1 & 0 & 0 \\
\hline $\begin{array}{l}\text { Severe osteoarthritis } \\
\quad(0=\text { No, } 1=\text { Yes })\end{array}$ & 0 & 1 & 1 & 1 & 0 & 0 \\
\hline $\begin{array}{c}\text { Low back pain } \\
(0=\text { No, } 1=\text { Yes })\end{array}$ & 1 & 1 & 1 & 1 & 0 & 0 \\
\hline $\begin{array}{l}\text { Anxiety/depression } \\
\quad(0=\text { No, } 1=\text { Yes })\end{array}$ & 1 & 1 & 1 & 1 & 0 & 0 \\
\hline $\begin{array}{l}\text { DPP4 therapy } \\
(0=\text { No, } 1=\text { Yes })\end{array}$ & 0 & 0 & 0 & 0 & 0 & 0 \\
\hline $\begin{array}{l}\text { SGLT2 therapy } \\
(0=\text { No, } 1=\text { Yes })\end{array}$ & 0 & 0 & 0 & 0 & 0 & 0 \\
\hline $\begin{array}{l}\text { GLP1r therapy } \\
(0=\text { No, } 1=\text { Yes })\end{array}$ & 0 & 0 & 0 & 0 & 0 & 0 \\
\hline $\begin{array}{l}\text { Insulin therapy } \\
(0=\mathrm{No}, 1=\text { Yes })\end{array}$ & 0 & 0 & 0 & 0 & 0 & 0 \\
\hline NLR & 107 & 1.1 & 1 & 1.6 & 1.3 & 1.1 \\
\hline Il-17A (pg/mL) & 1.53 & 0.68 & 0.01 & 0.68 & 1.47 & 1.42 \\
\hline $\mathrm{Il}-37$ (pg/mL) & 0.24 & 10.2 & 0.22 & 16.4 & 0.8 & 3.4 \\
\hline
\end{tabular}

Cl-cluster; BMI-body mass index; mac-midarm circumference; Hb-hemoglobin; NLR-neutrophil-to-lymphocyte ratio; eGFR - estimated glomerular filtration rate; TSH - thyroid-stimulating hormone; CRP-C-reactive protein; DM2-diabetes mellitus type 2; CHD—chronic heart disease; CAD—coronary artery disease; PAD—peripheral artery disease; DPP4—dipeptidyl peptidase-4 inhibitor; SGLT2-sodium-glucose cotransporter-2 inhibitors; GLP1r-glucagon-like peptide-1 receptor agonists. 
The MLR models with the markers NLR, Il-17A, and Il-37, used as the target outcome variables, are presented in Table 5.

Table 5. Multivariate linear regression analysis for NLR, Il-17A, and Il-37 variables as dependent variables.

$\begin{array}{r}\text { NLR }=-0.2602 \times \text { Gender }+0.0156 * \mathrm{BMI}+-0.0077 \times \text { eGFR in } \mathrm{mL} / \mathrm{min} / 1.73 \mathrm{~m}^{2}+-0.058 \times \text { eGFR levels }+-0.0813 * \text { Triglycerides }+ \\ -0.081 \times \mathrm{TSH}+0.0182 \times \mathrm{CRP}+0.3491 \times \text { Severe osteoarthritis }+0.0149 \times \mathrm{Il}-17 \mathrm{~A}+-0.0007 \times \mathrm{Il}-37+2.2697 \\ \hline \mathrm{Il}-17 \mathrm{~A}=0.0584 \times \text { age in years }+-1.1963 \times \text { eGFR levels }+0.0459 \mathrm{x}-\mathrm{xHDL}+0.3422 \times \mathrm{CRP}+0.0385 \times \mathrm{Il}-37+-0.8856 \\ \hline \mathrm{Il}-37=17.377 \times \text { eGFR levels }+-0.883 \times \mathrm{HDL}+-6.4164 \times \mathrm{TSH}+-4.9867 \times \mathrm{CRP}+17.3077 \times \mathrm{Il}-17 \mathrm{~A}+-15.2037\end{array}$

BMI-body mass index; NLR—neutrophil-to-lymphocyte ratio; eGFR-estimated glomerular filtration rate; TSH-thyroid-stimulating hormone; CRP_C-reactive protein; HDL_HDL cholesterol; IL-17A and IL-37_cytokines.

\section{Results}

In the group of 174 examined PC diabetic patients, males were more prevalent than females (Table 1). According to the selection criteria, patients were aged 50 years or above, and some of them were of very old age (over 85 years). Patients varied highly in number of years of having DM2. Most of them had hypertension, but the duration of hypertension varied greatly. Other major characteristics were high number of comorbidities ( $\geq 3$ in most) and high variations in anthropometric measures and laboratory tests, also including markers of inflammation. Serum concentrations of cytokine IL-37 were in the range between 0.14 and 258.8 , except for one patient, in whom a serum concentration of $1788.4 \mathrm{pg} / \mathrm{mL}$ was measured.

With respect to comorbidities, CVD was most prevalent; almost half of the patients had a diagnosis of CHD, and one-third of them were diagnosed with CAD. Musculoskeletal diseases were also common, and every second patient had markedly developed osteoarthritis. Mood disorders, diagnosed as anxiety/depression, were also highly prevalent, presenting in more than a third of patients. Patients were distributed across all levels of renal function. A high proportion of patients lacked physical robustness, showing signs of prefrailty or frailty.

Relatively small proportions of the examined patients had used some of the newgeneration antidiabetic medications, and less than a quarter of patients were under therapy with insulin.

It can be seen from Table 2 that the accuracy of the clustering procedure was higher in models with 5 or 6 clusters than in those with lower numbers of clusters. The user (family physician) made a decision about which one of two clusters with equal performance was more reliable from the clinical point of view.

At least three clinically interpretable phenotypes could be recognized in the group of examined diabetic patients (Table 3). Two phenotypes (clusters $\mathrm{Cl} 1 / 3$ and $\mathrm{Cl} 2 / 3$ ) referred to obese individuals (BMI $>30$ ) aged about 60 years; however, the first phenotype (cluster $\mathrm{Cl} 1 / 3$ ) was dominated by men, whereas the second (cluster $\mathrm{Cl} 2 / 3$ ) was dominated by women. Patients in these two clusters also differed from each other in the time when hypertension and DM2 began to emerge. In the dominantly male group, hypertension started in middle age, and DM2 developed recently (at the age of about 60). The dominantly female group had recently acquired both hypertension and DM2.

In contrast to these two clusters, cluster $\mathrm{Cl} 3 / 3$ was dominated by men of older age (about 70 years) who were not obese and who had had both hypertension and DM2 for a long period of time. Only patients in this cluster were frail, predominantly had atherosclerotic CVD (CAD and PAD), and had significantly decreased renal function (at stage 3).

It can be seen in Table 3 that the weighted values of the laboratory tests, triglycerides, HDL cholesterol, TSH, hemoglobin, and CRP varied across the clusters. Neither of the considered therapy options was prevalently used in any of the three clusters.

A condensed presentation of clinical profiles of individuals selected from particular clusters in the three-cluster model is provided in Figure 1. 

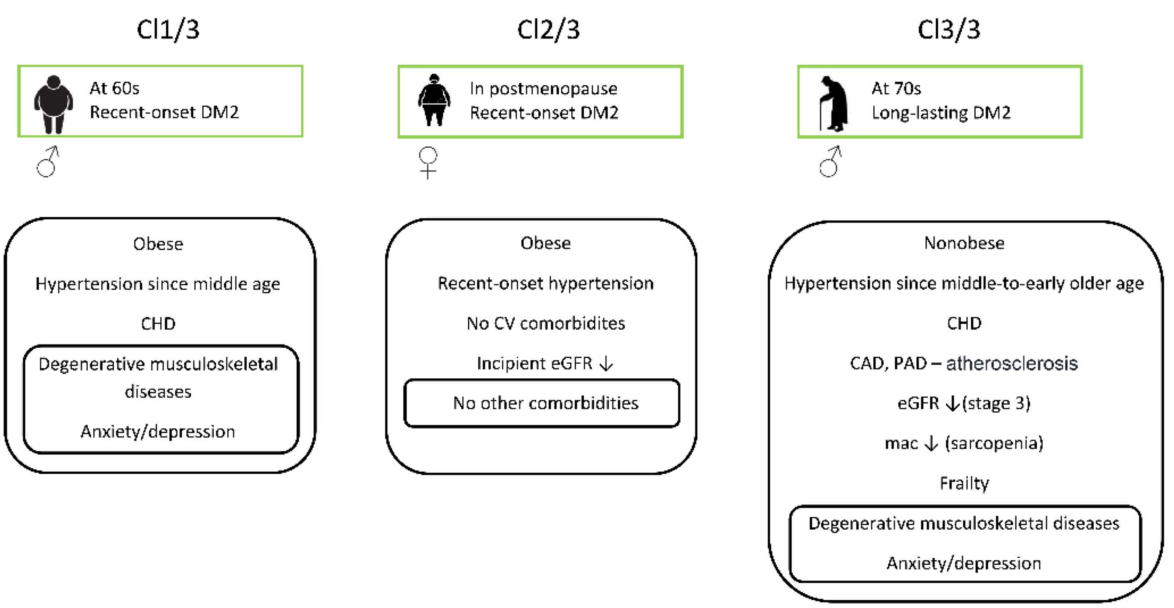

Figure 1. Sociodemographic and clinical contexts of patients in the clusters identified by the 3-cluster model. $\mathrm{Cl}$-cluster; DM2-diabetes mellitus type 2; mac-midarm circumference; $\mathrm{CV}$ - cardiovascular; $\mathrm{CHD}$ — chronic heart disease; CAD—coronary artery disease; PAD—peripheral artery disease; eGFR — estimated glomerular filtration rate.

In the clusters identified by the three-cluster model, patterns of the inflammatory markers NLR, IL-17A, and IL-37 also differed from each other (Figure 2). For all of these markers, serum concentrations were higher in patients in cluster $\mathrm{Cl} 2 / 3$ than in patients in cluster $\mathrm{Cl} 1 / 3$. When clusters $\mathrm{Cl} 2 / 3$ and $\mathrm{Cl} 3 / 3$ were compared with each other, the opposite directions for cytokines IL-17A and IL-37 could be observed. While the values for cytokine IL-17A were lower, the values of cytokine IL-37 were higher in cluster $\mathrm{Cl} 3 / 3$ than in cluster $\mathrm{Cl} 2 / 3$. Cluster $\mathrm{Cl} 3 / 3$ was curious in that serum concentrations of cytokine IL-37 were markedly increased.

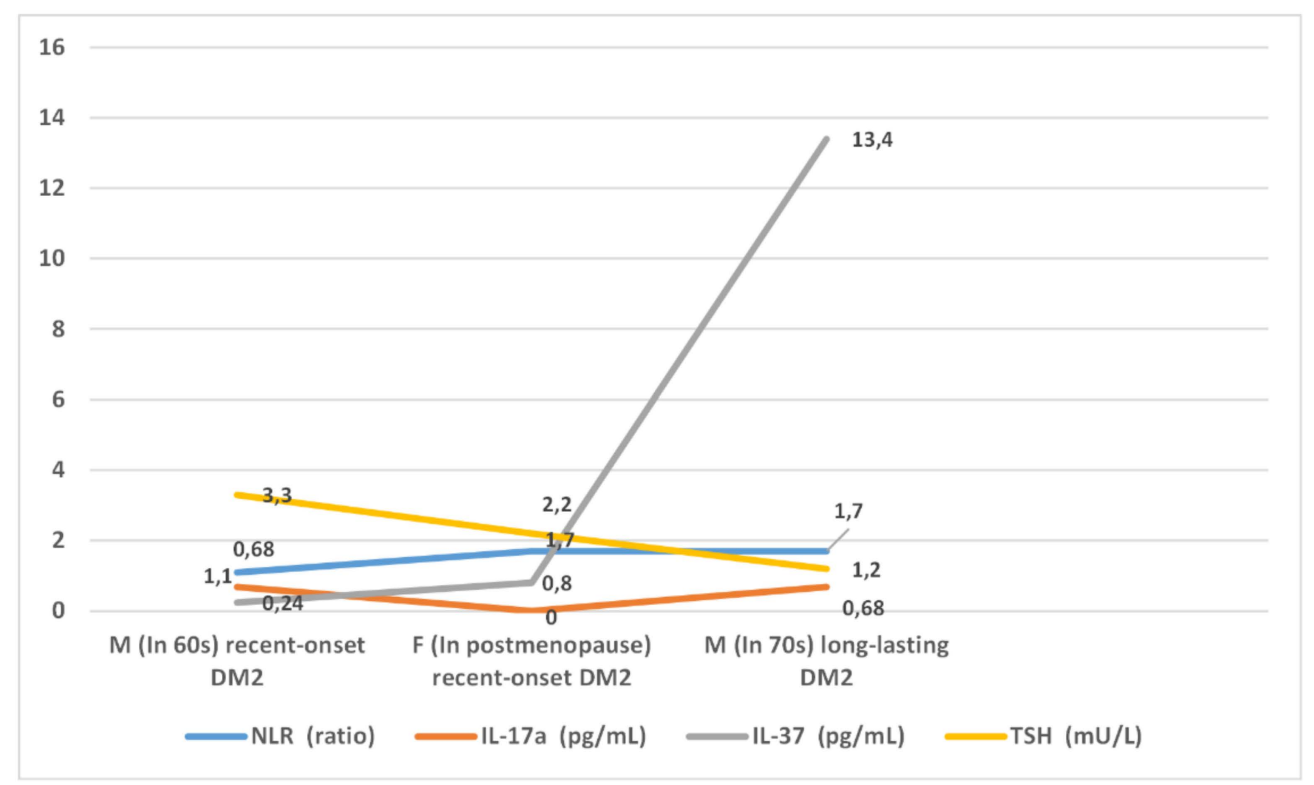

Figure 2. A graphical presentation of the inflammatory markers NLR, IL-17A, and IL-37, and the hormone TSH across the clusters in the three-cluster model. M-males; F-females; DM2-diabetes mellitus type 2; NLR—neutrophil-to-lymphocyte ratio; Il-17A—cytokine IL-17A; IL-37—cytokine IL-37; TSH-thyroid-stimulating hormone. 
It was evident from the six-cluster model that a variety of phenotypes may exist among patients with DM2 (Table 4). When comparing the patterns of the sociodemographic and clinical characteristics of patients in the clusters, indicated by age, gender, $\mathrm{CV}$ comorbidities, levels of renal function decline, and hypertension and DM2 duration and time of onset, some new knowledge is provided. For example, incident DM2 occurs at the age of around 60, but came in several subtypes (clusters $\mathrm{Cl} 2 / 6, \mathrm{Cl} 5 / 6$, and $\mathrm{Cl} 6 / 6$ ), depending on the time when hypertension developed and on whether men or women were predominant in the cluster. Other phenotypes referred to patients with late-onset DM2 (in their 70 s), such as those in cluster $\mathrm{Cl} 3 / 6$, or to patients with long-lasting DM2 (clusters $\mathrm{Cl}$ $1 / 6$ and $\mathrm{Cl} 4 / 6$ ), which profiles nevertheless differed from each other based on differences in the prevailing age, gender, and time of DM2 onset.

By further comparing the six clusters, we could see that fairly low renal function (stage 3) could be expected in diabetic patients of advanced age (in their 70s and 80s) and in those with long-term hypertension duration (clusters $\mathrm{Cl} 3 / 6$ and 4/6). Only these two oldest groups of diabetic patients were also featured with multiple CV comorbidities. Although similar in many features, these two patient groups yet differed from each other in an important aspect of health, the frailty status.

As in the three-cluster model, in the six-cluster model, there was a lack of variation in variables indicating therapeutic options.

A condensed presentation of the sociodemographic and clinical profiles of individuals selected from particular clusters in the six-cluster model is provided in Figure 3.
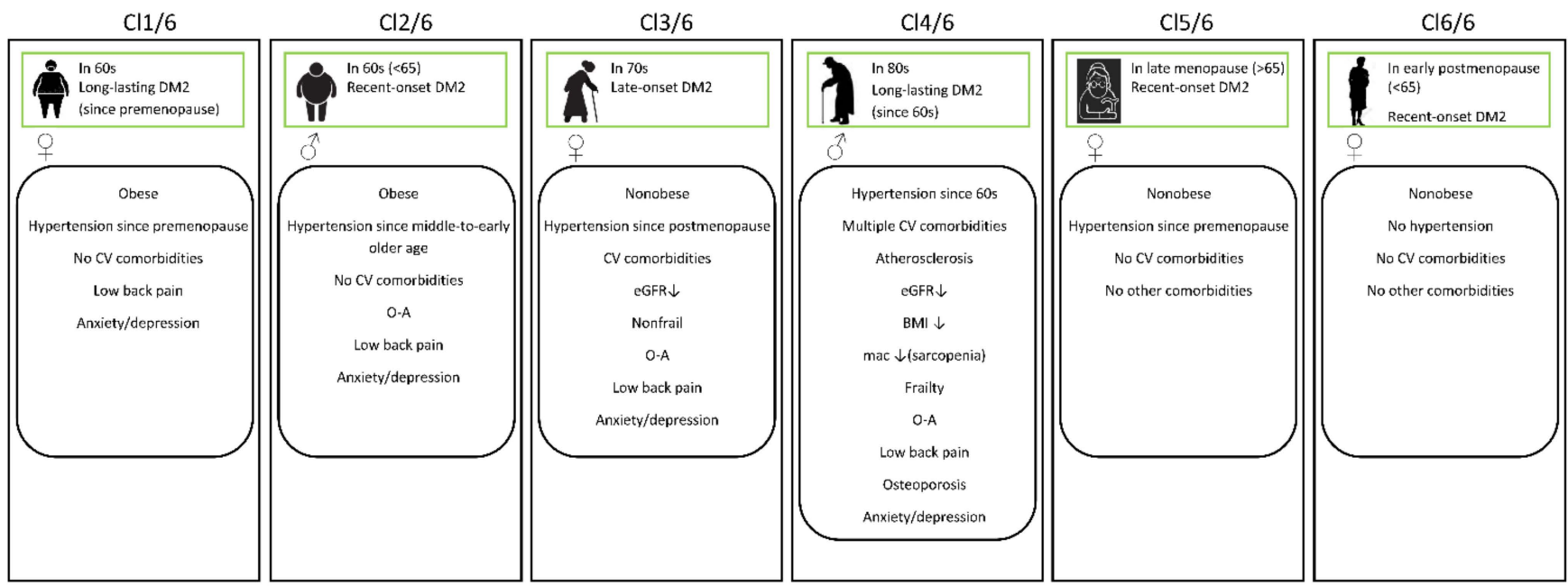

Figure 3. Sociodemographic and clinical contexts of patients in the clusters identified by the 6-cluster model. $\mathrm{Cl}$-cluster; DM2—diabetes mellitus type 2; BMI—body mass index; mac-midarm circumference; CV-cardiovascular; $\mathrm{O}-\mathrm{A}$-osteoarthritis; eGFR — estimated glomerular filtration rate.

A graphical presentation of the inflammatory markers NLR, IL-17A, and IL-37 across the clusters is provided in Figure 4. 


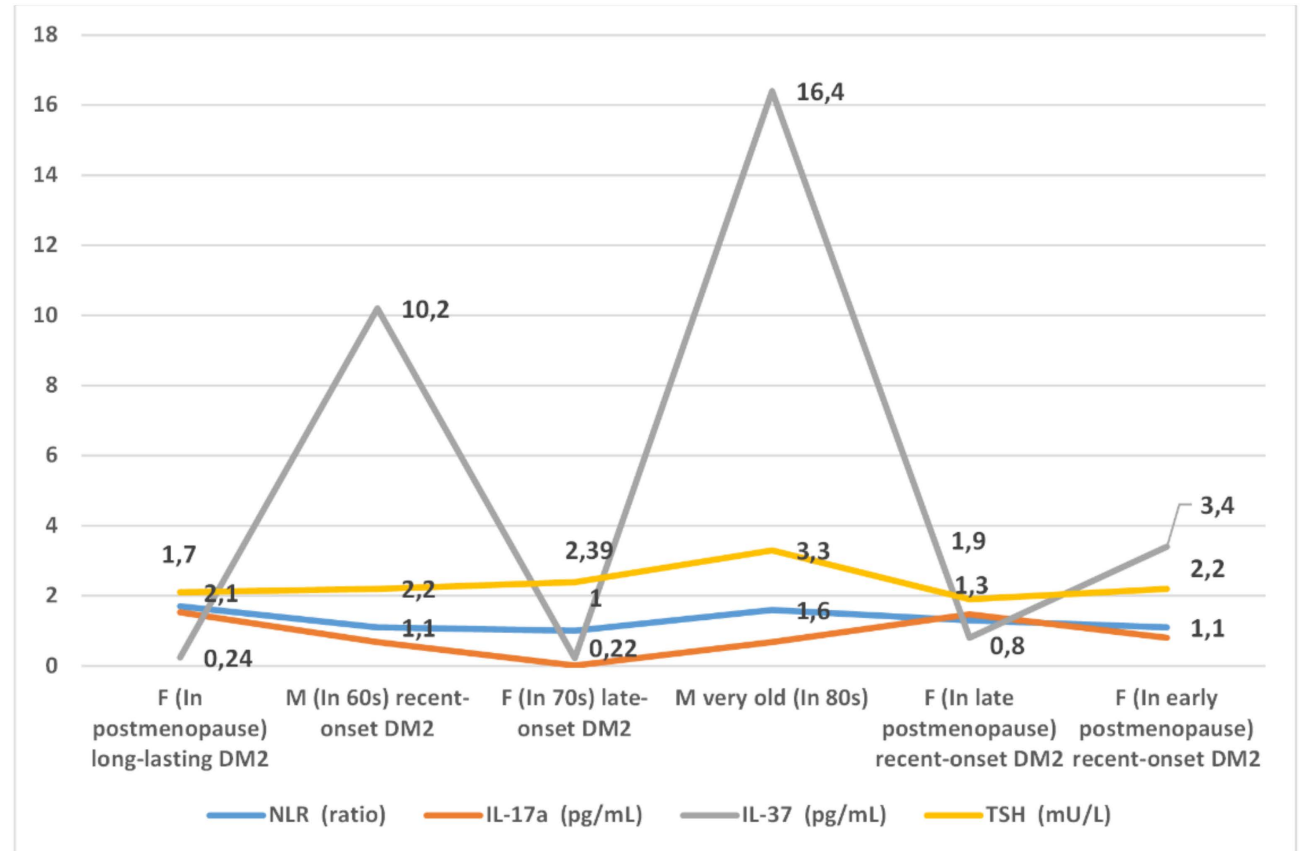

Figure 4. The graphical presentation of inflammatory markers NLR, IL-17A, and IL-37, and the hormone TSH, across the clusters, in the 6-cluster model. M-males; F-females; DM2-diabetes mellitus type 2 .

When comparing the clinical and sociodemographic contexts and patterns of the inflammatory markers NLR, IL-17A, and IL-37 in the clusters identified by the three- and six-cluster models, we could draw some parallels and find out some new cluster subtypes that were hidden in the three-cluster model (Figure 5).

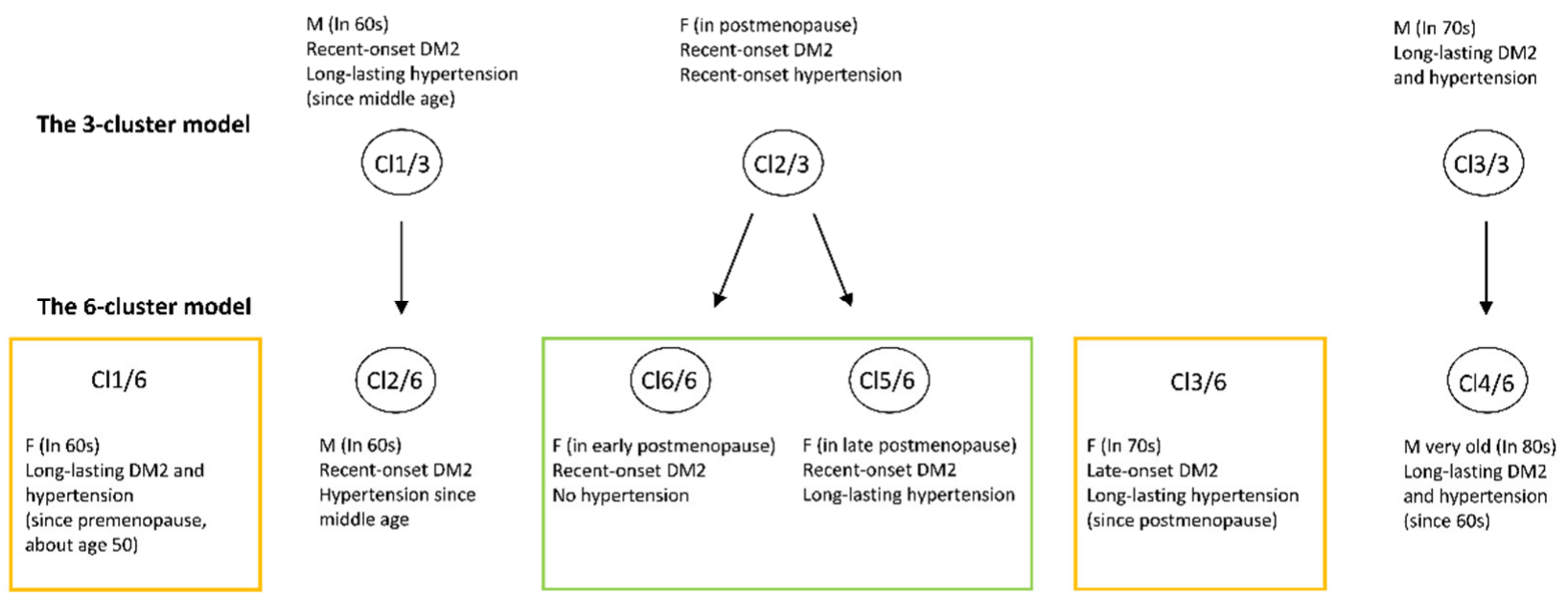

Figure 5. Diversification of the phenotypes when the number of clusters increased from 3 to 6 . Clusters framed in green color, in the 6-cluster model, are proposed to be derived from the "parent" clusters in the 3-cluster model; Clusters Cl $1 / 6$ and $\mathrm{Cl} 3 / 6$, framed in yellow color, were newly identified subtypes. $\mathrm{Cl}$-cluster; $\mathrm{M}$-males; F—females; DM2—diabetes type 2.

It can be seen from Figure 5 that a separation of the "parent" clusters into new cluster subtypes was not consistent. The clusters that stayed in their "parent" clusters when the $\mathrm{k}$-value increased were those dominated by the male gender (the pairs $\mathrm{Cl} 1 / 3-\mathrm{Cl} 2 / 6$ and $\mathrm{Cl} 3 / 3-\mathrm{Cl} 4 / 6$ ). The cluster $\mathrm{Cl} 2 / 3$ in the three-cluster model, which refers to women in postmenopause and with recent-onset DM2, spread out in the six-cluster model into 
two new subtypes $(\mathrm{Cl} 5 / 6$ and $\mathrm{Cl} 6 / 6)$, of which the first represented women in early postmenopause and the second represented women in late postmenopause. Accordingly, these two new cluster subtypes differed from each other in hypertension duration. There were also two new cluster entities that were revealed when the k-value increased from three to six. One of them $(\mathrm{Cl} 1 / 6)$ indicated women in postmenopause but with long-lasting DM2, and the other $(\mathrm{Cl} 3 / 6)$ indicated women of older age (about 70 years) with recent-onset DM2, which was therefore termed as late-onset DM2. It can be seen from Figure 6 that variations in the inflammatory markers IL-37 and IL-17A were higher than those in the inflammatory marker NLR and in TSH.

Variations among 6 clusters in average scores on the selected variables when compared with the entire sample.

5,00

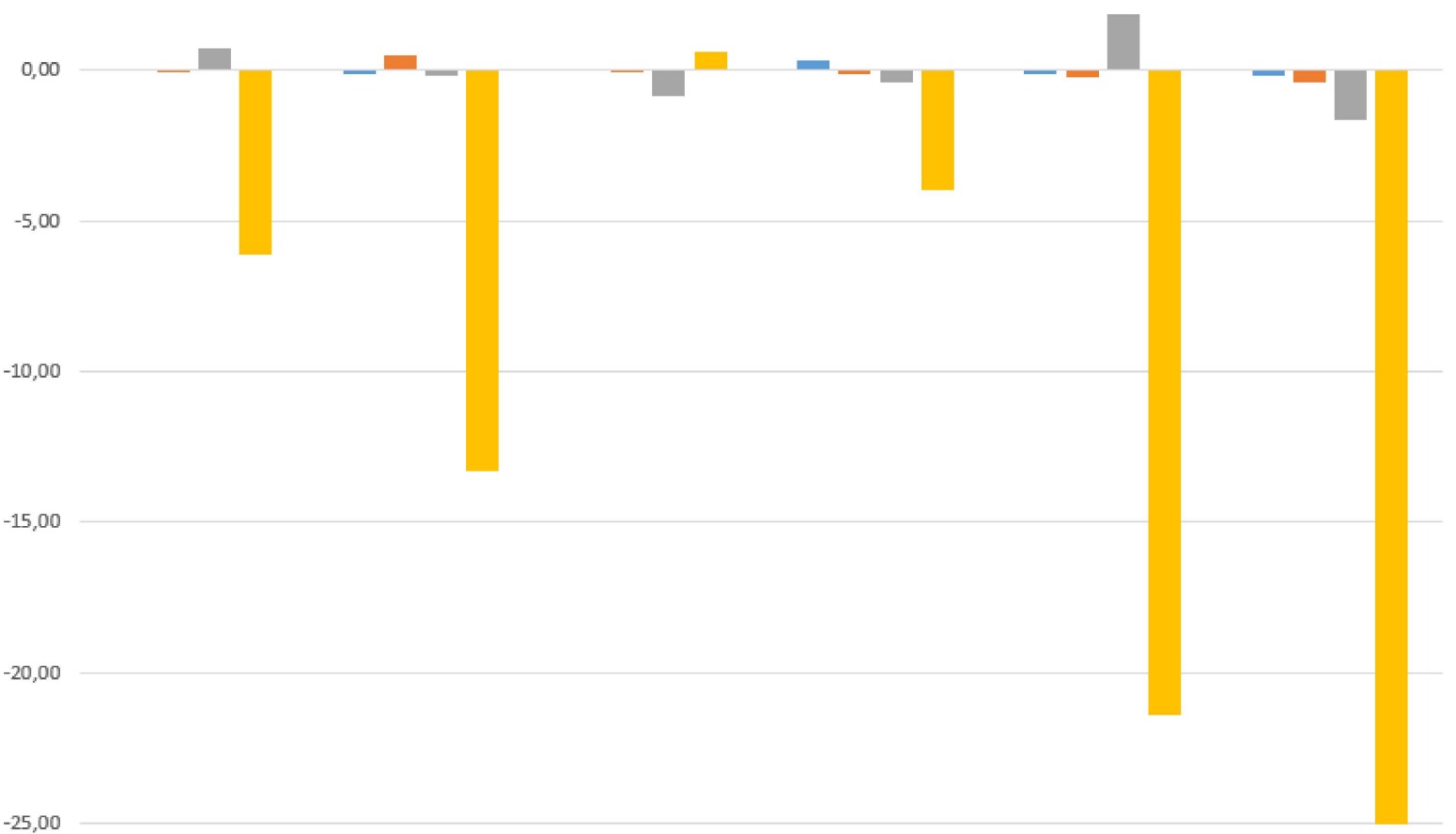

$-25,00$

\begin{tabular}{|c|c|c|c|c|c|c|}
\hline$-30,00$ & $\mathrm{Cl} 1 / 6$ & $\mathrm{Cl} 2 / 6$ & $\mathrm{Cl} 3 / 6$ & $\mathrm{Cl} 4 / 6$ & $\mathrm{Cl} 5 / 6$ & $\mathrm{Cl}_{6} / 6$ \\
\hline$\square$ NLR & 0,00 & $-0,13$ & 0,05 & 0,32 & $-0,13$ & $-0,17$ \\
\hline ISH & $-0,07$ & 0,51 & $-0,01$ & $-0,14$ & $-0,23$ & $-0,43$ \\
\hline WIL-17a & 0,72 & $-0,21$ & $-0,87$ & $-0,42$ & 1,82 & $-1,68$ \\
\hline IIL-37 & $-6,14$ & $-13,30$ & 0,58 & $-4,01$ & $-21,39$ & $-24,99$ \\
\hline
\end{tabular}

Figure 6. Variations in inflammatory markers NLR, IL-17A, and IL-37 and in the hormone TSH among the clusters in the 6-cluster model. Cl—cluster; NLR—neutrophil-to-lymphocyte ratio; Il-17A—cytokine IL-17A; IL-37—cytokine IL-37; TSH-thyroid-stimulating hormone. The average scores of the selected variables were transformed in a way to show the justified units, which could be be above or below the average of the sample.

The MLR models presented in Table 5 indicate variables that significantly correlated with any of the emerging inflammatory markers, including NLR and the cytokines IL-17A and IL-37. The models had in common that all of these markers were associated with decreased renal function and with each other, but the directions of these associations were different. For example, while the values of the markers NLR and IL-17A were higher in less-graded stages of renal function decline, the values of the marker IL-37, in contrast, 
increased as the stages of renal function decline became higher. The marker NLR was associated positively with the cytokine IL-17A but negatively with the cytokine IL-37. The cytokines IL-17A and IL-37 were positively associated with each other, but serum concentrations of cytokine IL-37 were much more dependent on the levels of cytokine IL-17A (as indicated by the IL-37-related MLR model) compared to the cytokine IL-17A, the serum values of which were less strongly dependent on the levels of the cytokine IL-37 (as indicated by the IL-17A-related MLR model).

Interesting in these models, too, was that higher BMI and some comorbidities, such as osteoarthritis, impacted the rise in NLR values but did not affect the other two markers of inflammation. Metabolic syndrome-related and insulin resistance-related dyslipidemia, indicated by increased triglycerides and decreased HDL cholesterol, were positively associated only with the marker IL-37, while on the contrary, the markers NLR and IL-17A were higher when there were no signs of metabolic syndrome. The regulation of the markers NLR and IL-37 was associated with activation of the hypothalamic-pituitary-thyroid axis (NLR-related and IL-37-related MLR models), and this association was much stronger in the case of the marker IL-37.

\section{Discussion}

Patients with DM2 usually have multiple comorbidities, which increases interindividual variability and requires more patient-centered (personalized) management and medications [50,65]. Some comorbidities are conventionally considered as CV risk factors, some as diabetic complications, and some as accompanying (unrelated) to DM2. Recent knowledge about the common pathophysiological background of these comorbidities, with inflammation being in the center of the pathophysiological networks, has indicated that a more integrated approach is needed for classifying these disorders $[2,6,65]$.

Distinctly from acute inflammation, for which the time course is well known, the phases of chronic inflammation that are associated with aging and the development of chronic age-related diseases are poorly identified; only some isolated mechanisms have been discerned [66,67]. The mechanisms of chronic inflammation are yet thought to show dynamics of change that run in parallel with advancement in end-organ damage and decline in whole-body entropy [3,4]. Regarding patients with DM2, the broken pieces of knowledge-how DM2 usually develops in obese individuals, how adipose tissue is a source of inflammation, how inflammatory mechanisms are implicated in the development of comorbidities, and how accumulated comorbidities exhaust homeostasis reserves and promotes frailty - need to be better integrated $[9,19]$. Thanks to the availability of new methodologies for data analysis, we have started to integrate this knowledge $[16,17,65]$.

In this study, we aimed to identify the patterns of inflammatory markers that are involved in certain clinical contexts, determined by age and gender of patients with DM2 and including also information on DM2 and hypertension duration and the time of onset, as the core framework for determining these patterns. By keeping in mind that the scored values of markers of inflammation stay in a balance with the net effect of disorders that can influence their values, phenotypes indicated by the clusters provided insights into the phases of inflammatory responses that are involved in strictly defined clinical frameworks, thus being reflective of the dynamics of developing DM2-associated comorbidities [3,68].

The identified clusters can be used for risk assessment and individualized management of diabetic patients and for planning future research. In particular, in longitudinal studies, these results could show which clusters lead to which outcomes by which rates of change. Knowing these relationships would be of the utmost importance for planning prevention.

The reasoning behind the clusters is illustrated by the in-depth analysis of the threecluster model. An advantage of this model over the six-cluster model is that it is simpler and thus enables a clearer view of how patient sociodemographic and clinical characteristics are balanced with the patterns of inflammatory markers. This analysis, e.g., showed that patients in cluster $\mathrm{Cl} 2 / 3$, who featured female gender, obesity, age around 60, and 
new-onset hypertension and DM2, fit well to the evidence indicating that women usually start to gain weight and obesity-associated disorders, such as hypertension and DM2, in the years that come after menopause [69]. This all-at-once accumulation of multiple metabolic and vascular factors is expected to promote end-organ damage faster than in cluster $\mathrm{Cl} 1 / 3$, in which patients were of similar age but had different dynamics of $\mathrm{CV}$ risk factor accumulation, since hypertension preceded the onset of DM2 by years. Accordingly, patients in cluster $\mathrm{Cl} 2 / 3$ showed higher serum concentrations of the inflammatory markers NLR and IL-17A than patients in cluster $\mathrm{Cl} 1 / 3$. In this regard, and as the evidence has also indicated, these inflammatory markers are likely to reflect the magnitude of inflammation that is evoked by inflammatory cell accumulation on the surface of dysfunctional vascular endothelial cells, and thus also the patient capacity for target tissue damage [21,31,32]. The development of CVD in these patients may yet be postponed, which is associated with the fact that patients in this cluster were dominantly women. In this regard, the evidence has suggested that women in early postmenopause have vascular endothelial cells relatively preserved from inflammatory cell adhesion compared to those of age-matched men, which can protect, for a while, target organs from inflammation-mediated damage [70,71]. Because there is a lag in time between when CV risk factors start to act on vascular endothelial cells, reverting them into being dysfunctional, and when the significant CV pathology develops, patients in cluster $\mathrm{Cl} 2 / 3$ were not featured with marked CV comorbidities but had only initially impaired renal function $(\mathrm{eGFR}<60)$ [41]. The low intensity of tissue-related inflammation in patients in cluster $\mathrm{Cl} 1 / 3$, on the contrary, could not evoke a sufficient suppressive response (as proved by low values of the suppressive cytokine IL-37), and systemic compensatory anti-inflammatory mechanisms had to take place (as proved by higher TSH) [72].

Unlike clusters $\mathrm{Cl} 1 / 3$ and $\mathrm{Cl} 2 / 3$, which referred to patients with recent-onset DM2, cluster $\mathrm{Cl} 3 / 3$ referred to patients of older age (around 70), mostly males, in whom hypertension and DM2 had been present for a long time, since their middle age. Epidemiological data have indicated that hypertension and DM2 start earlier in life in men than in women [73]. In line with their older age and long-lasting main CV risk factors, as the evidence has also suggested, patients in cluster $\mathrm{Cl} 3 / 3$ had multiple $\mathrm{CV}$ comorbidities, including atherosclerotic CVD (CAD and PAD) and fairly low renal function (level 3) $[13,26,74]$. Specifically, it is known that men are more predisposed to atherosclerotic diseases than women [26]. Taking this all into account, it is not surprising that frailty was featured only in patients in cluster $\mathrm{Cl} 3 / 3$. Frailty is known to develop in older individuals with multiple comorbidities, in particular CVD, CKD, and DM2 [75-77]. The pattern of laboratory tests fit to this clinical context, as seen by lower $\mathrm{Hb}$ and $\mathrm{HDL}$ cholesterol and higher triglycerides than in the other two clusters, which could have been the effect of lower renal function and frailty $[13,38,78]$. The frailty in patients in this cluster could also explain the somewhat distorted body shape, as shown by the modest "BMI" values combined with disproportionally lower "mac" values, indicating more muscle than weight loss. This can be the case when frailty develops in previously obese individuals [19,79].

As suggested by positive correlations between the marker NLR and the cytokine IL-17A and CRP, in the MLR model in which NLR was an outcome measure, during the progression phase of end-organ damage, there was a positive inflammation regulation loop. In this regard, the cytokine IL-17A is known to act as a propagator of tissue cell infiltration associated with end-organ damage [30-32].

In advanced phases of the end-organ damage progression, however, and when serum concentrations of the cytokine IL-17A increase to some extent, it is time for the suppressive cytokine IL-37 to take up a role. This scenario was suggested by higher values of the cytokine IL-37 in cluster $\mathrm{Cl} 2 / 3$ than in cluster $\mathrm{Cl} 1 / 3$ and by this cytokine being markedly increased in cluster $\mathrm{Cl} 3 / 3$, wherein the cytokine IL-17A remained low. The positive correlations between the cytokines IL-17A and IL-37, as demonstrated in the MLR models in which either the cytokine IL-17A or the cytokine IL-37 were outcome measures, further supported this argument. In particular, in the MLR model in which the cytokine IL-37 was 
an outcome measure, this correlation was very strong, indicating strong dependence of the cytokine IL-37 on even small rises in serum concentrations of the cytokine IL-17A, which goes in line with the suppressor-regulatory role of the cytokine IL-37.

Further in this context, the strong positive correlation of the cytokine IL-37 with higher levels of renal function decline in the IL-37-related MLR model could be a sign of the body's efforts to suppress the overwhelming inflammation in conditions characterized by exhaustion of homeostatic mechanisms and could be associated with frailty. In this way, our results supported the evidence indicating the cytokine IL-37 as having broad anti-inflammatory and modulatory effects [33]. One of the modes of action of this cytokine may be by decreasing the level of insulin resistance [34]. Chronic renal failure is also known to be an insulin-resistant state associated with metabolic syndrome-related disorders [80]. This in our results was supported by the lower HDL cholesterol and higher triglycerides in cluster $\mathrm{Cl} 3 / 3$ than in the other two clusters and by the negative correlation of the cytokine IL-37 with HDL cholesterol in the IL-37-related MLR model. An intriguing hypothesis that arose from the analysis of the clusters in the three-cluster model is that activation of the hypothalamic-pituitary-thyroid axis might represent a systemic defense mechanism triggered during the progression phase of end-organ damage in order to revert the sloweddown energy metabolism and to retard the dissemination of inflammatory cells to the tissues [72,81]. This notion was supported by the higher TSH values (at the upper border of the reference range) in patients in cluster $\mathrm{Cl} 1 / 3$ than in the other two clusters and by the negative correlation between TSH and the marker NLR in the NLR-related MLR model. When tissue-related defense mechanisms are going to become exhausted because of overwhelming tissue infiltration by inflammatory cells and fibrotic processes prevailing over inflammation processes, as in conditions associated with multiple CV comorbidities and frailty, there could be also a breakdown of the systems regulating these mechanisms. In our results, this was likely indicated by low TSH values in patients in cluster $\mathrm{Cl} 3 / 3$ and by the negative correlations of the cytokine IL-37 with both TSH and CRP in the MLR model in which IL-37 was an outcome measure. The cytokine IL-37 was found to rise in conditions associated with fibrosis [33]. The acute-phase reactant CRP is known for its multiple inflammation-regulating roles [82].

The diversification of the cluster subtypes when the k-value increased from three to six revealed that in older individuals with DM2, mainly women contributed to the expansion of the phenotypes. A similar conclusion was drawn by some other authors on a large scale [65]. For this reason, in future studies with similar design, men and women should be considered separately. The same was indicated by the epidemiological data. In this regard, it was shown that the gender-dependent differences in the life courses of hypertension, metabolic syndrome, and DM2 influenced differences in the dynamics of CV risk factor accumulation and CVD development $[69,73]$. As identified in the study of Corrao et al., there are differences in the structure of comorbidities between older men and women [83]. Furthermore, in this study, sex dimorphism may have influenced the distribution of comorbidities in the clusters. Specifically, in women, as we emphasized in our previous studies, the transition from pre- to postmenopause and the early postmenopausal period are critical periods in women's lives when CV risk factors are significantly modified, which specifically in women can add to the diversity of DM2-related phenotypes $[44,68]$. Some other studies have also provided important insights into the reasons for the heterogeneity of older patients with DM2, indicating factors such as the current patient age and DM2 duration and age of onset [41].

Known factors that could influence variations in inflammatory markers in patients with DM2, as evidence has suggested, include both age-dependent changes in the immune system and gender-dependent differences in inflammatory response [22,26]. Of not less importance, there could be an interdependence between the course of aging, either successful or unsuccessful, and the level of inflammation, which in great part is influenced by lifestyles and environmental factors $[1,4,22]$. Specifically, in women, the decline in the sex hormones that occurs during the menopausal transition may additionally influence immune and 
inflammatory responses [31]. Another question that deserves attention when evaluating inflammatory markers in older patients with DM2 is whether or not frailty has developed. This is important because this condition can alter, in an unexpected way, anthropometric measures and laboratory tests, including the values of inflammatory markers [79,84].

In this study, all these pieces of evidence were lumped together and helped explain variations in the selected set of inflammatory markers. We could see how different combinations of factors, such gender, age, DM2 duration and age of onset, and the effect of some treatments, were associated with some $\mathrm{CV}$ risk factors, body shape characteristics, and CV and non-CV comorbidities, as well as how inflammatory markers were justified among these multifaceted patterns. Although it is not possible to fully understand all associations between variations in inflammatory markers as expressed by the six-cluster model and the diversity of the identified phenotypes, we could draw some general conclusions from these obtained results. The longitudinal follow-up of patients in the clusters in associations to specific outcomes could give more detailed insights in this regard.

It was evident from the results obtained by the six-cluster model that variations in inflammatory markers that are already established in clinical practice, such as CRP and NLR, were lower than variations in the cytokines IL-17A and IL-37, which justifies the usefulness of these cytokines for routine use. The cytokine IL-37 was shown to be especially more distinctive than other explored markers. However, the fact that this cytokine increased only in some specific situations limits its use as a single deciphering marker. Furthermore, the marker NLR, if used alone, as we discussed in our previous review paper, can hardly differentiate between the subgroups of women who are in the age around menopause or in early postmenopausal period (age range 50-65 years), in spite of the fact that they may differ from each other in CV and metabolic profiles. Furthermore, this marker, when used alone, cannot differentiate between women of this age and age-matched men [31]. The results of this study indicated the same. Specifically, although the NLR scores were similar, e.g., in clusters $\mathrm{Cl} 1 / 6$ and $\mathrm{Cl} 4 / 6$, the characteristics of patients in these clusters were nonetheless different. When, however, the cytokine IL-17A was also considered, the higher values of this cytokine in cluster $\mathrm{Cl} 1 / 6$ than in cluster $\mathrm{Cl} 4 / 6$ likely indicated the higher potential of patients in cluster $\mathrm{Cl} 1 / 6$ than those in $\mathrm{Cl} 4 / 6$ to develop tissue-related inflammation progression. Taken together, the results of this study indicated that it is better to use a set of inflammatory markers, than any single one, to discern among the phenotypes of patients with DM2.

We gained further insights into how the set of inflammatory markers indicated different phases of chronic inflammation associated with DM2-related end-organ damage when analyzing clusters $\mathrm{Cl} 1 / 6, \mathrm{Cl} 5 / 6$, and $\mathrm{Cl} 6 / 6$ of the six-cluster model. These clusters had in common a prevailing female gender and a lack of $\mathrm{CV}$ comorbidities. They differed from each other, however, in patterns of inflammatory markers, reflecting differences in the potential of individuals in these clusters to develop end-organ damage and $\mathrm{CV}$ complications. In this regard, women in cluster $\mathrm{Cl} 1 / 6$ may have been in a less favorable position than their counterparts in cluster $\mathrm{Cl} 5 / 6$ based on the former's higher values of the markers NLR and IL-17A, and in parallel to this, their lower values of the cytokine IL-37. This pattern of inflammatory markers in patients in cluster $\mathrm{Cl} 1 / 6$ may be reflective of the long-term duration of both main CV risk factors, DM2 and hypertension, and/or of DM2 onset earlier in life. In this regard, other studies have shown that the potential for complications to develop in patients with DM2 is higher when the age of DM2 onset is lower [41].

In a better position than these two patient subgroups, with respect to $\mathrm{CV}$ prognosis, may have been women in cluster $\mathrm{Cl} 6 / 6$. This was supported by even lower values of the markers NLR and IL-17A, albeit higher values of the cytokine IL-37, in women in this cluster than in those in the other two. This better inflammatory profile was in line with a more favorable $\mathrm{CV}$ risk profile of women in cluster $\mathrm{Cl} 6 / 6$, as indicated by the lack of obesity and hypertension. 
If, however, we bring together evidence indicating that the serum concentrations of the cytokine IL-37 rise in parallel to the level of insulin resistance and our results obtained by the six-cluster model, we can gain some further insights into associations between the phases of chronic inflammation and the progression rates of end-organ damage in patients with DM2 [34]. In this regard, we can see that higher values of the cytokine IL-37 appeared not only in patients in cluster $\mathrm{Cl} 4 / 6$ but in those in clusters $\mathrm{Cl} 2 / 6$ and $\mathrm{Cl} 6 / 6$. Taking into account the common features of these two clusters, higher values of the cytokine IL-37 can be expected in individuals with recently acquired DM2 and who are younger than 65, which may be a basis for their high potential for developing complications, than when DM2 occurs later in life, after the age of 65 (as in cluster $\mathrm{Cl} 5 / 6$ ) [41]. Seeing it this way, it may be that women in cluster $\mathrm{Cl} 6 / 6$ had an equal or even worse $\mathrm{CV}$ risk than women in cluster $\mathrm{Cl} 5 / 6$, in spite of the fact that both groups lacked CV comorbidities. Only longitudinal studies can give a clear answer to this dilemma.

As the last example for discussion, we use the two oldest patient groups in the sixcluster model, clusters $\mathrm{Cl} 3 / 6$ and $\mathrm{Cl} 4 / 6$. The common features of these clusters were low renal function and multiple $\mathrm{CV}$ and other comorbidities. However, these clusters markedly differed from each other in patterns of inflammatory markers. The values of these markers were lower in patients in cluster $\mathrm{Cl} 3 / 6$; in fact, these values were at the lowest levels in this cluster out of all of the identified clusters. The characteristics of patients in this cluster that could explain such a pattern of inflammatory markers could be late-onset DM2 (at the age of 70) and female gender. In this regard, the evidence has suggested that the onset of DM2 in advanced age, after the age of 70 or at age 80 , bears low risk of preterm mortality [41]. As we shown on the example of the marker NLR, the capacity for inflammatory cell dissemination throughout the tissues may in postmenopausal women be low [31]. The low values of inflammatory markers were not merely a sign of homeostatic mechanism exhaustion; the proof of this may be the lack of frailty in patients in cluster $\mathrm{Cl} 3 / 6$.

In contrast to cluster $\mathrm{Cl} 3 / 6$, the prominent feature of patients in cluster $\mathrm{Cl} 4 / 6$ was frailty. In line with this feature, there was a much higher score value of the suppressive inflammatory marker IL-37 in patients in this cluster, indicating advanced stages of endorgan damage and vascular complication development associated with fibrotic processes prevailing over inflammatory processes $[31,33,85]$. This, however, may not be a bad prognostic sign, taking into account the evidence that an increase in IL-37 occurs in conditions with increased insulin resistance, which in very old males, in spite of the presence of overt atherosclerotic disease, can be a sign of longevity [5,26,34]. In this way, our results supported the view of aging as a process of remodeling rather than of straightforward decline in homeostatic reserves [86].

From the same perspective we can see inconsistent results between the three-cluster and six-cluster models relating to the values of the hormone TSH. The values of this regulatory hormone took the opposite magnitudes in two complementary clusters, $\mathrm{Cl} 1 / 3$ in the three-cluster model and $\mathrm{Cl} \mathrm{4/6}$ in the six-cluster model. Based on the existing knowledge and our results, and including the strong negative correlation between these two markers in the IL-37-related MLR model, there may be a strict feedback loop between the cytokine IL-37 and the hormone TSH [33,72]. In this context, the hormone TSH could be another key deciphering factor for discerning among DM2-related phenotypes, which may have also prognostic and therapeutic relevance.

A separation of older patients with DM2 into discrete phenotypic subgroups, as done in this study, may be a way of deconstructing these patients' complexity and can be used as a model for guiding personalized treatment. This research approach could be especially beneficial for family physicians, who are in the position of dealing with the complexity of these patients on a daily basis.

For example, very old patients with $\mathrm{CV}$ comorbidities and frailty, as in cluster $\mathrm{Cl}$ $4 / 6$, in spite of increased insulin resistance, should not be treated with insulin-sensitizer drugs, or with many medications at all. Rather, they should be provided with general 
care and nutritional support. For women with high values of the inflammatory markers NLR and IL-17A combined with low IL-37 values, as in cluster Cl 1/6, a solution may be an anti-inflammatory treatment or an IL-37-based therapy. For women with modest $\mathrm{CV}$ risk and inflammatory profiles, such as those in cluster $\mathrm{Cl} 6 / 6$, on the contrary, only nonpharmacological and lifestyle-modifying measures should be enough. Finally, for women in cluster $\mathrm{Cl} 3 / 6$, who might have a low potential for the advancement of $\mathrm{CV}$ comorbidities and who suffer from affective disorders (e.g., anxiety/depression), recommendations for physical activity and cognitive behavioral therapy may be an optimal care option. These theoretically proposed treatment protocols should, however, first be assessed by prospective evaluations.

\section{Conclusions}

DM2 is a leading public health concern associated with multiple comorbidities, of which CVD has the most important prognostic role. Initiatives are emerging for a more personalized approach to managing patients with DM2. Chronic inflammation is considered to be a major force driving the development of DM2 and its associated comorbidities. Currently, there is no consensus as to which markers of inflammation best represent which phases of chronic inflammatory response. In this study, we aimed to show that by using a set of inflammatory markers clustered with variables indicating the sociodemographic and clinical contexts of diabetic patients, it is possible to identify different, reasonable phenotypes that may exist among diabetic patients. By analyzing the intra- and intercluster patterns of inflammatory markers, it was possible to recognize clinical contexts in which different mechanisms of chronic inflammation were involved. The approach presented in this paper might offer a reliable new strategy for personalized risk stratification and management of diabetic patients. More generally, if implemented in everyday practice of PC physicians, this research approach could promote the development of new, integrated strategies for managing older individuals with multiple chronic conditions.

Author Contributions: Conceptualization, L.T.M. and T.W.; methodology, L.T.M., P.Y. and Z.B.; software, P.Y. and F.B.; validation, L.T.M., P.Y., F.B., I.Š. and T.W.; formal analysis, L.T.M., F.B., I.Š. and Z.B.; investigation, L.T.M., Z.B., I.Š., I.M. and F.B.; resources, P.Y., Z.B., F.B., I.M. and I.Š.; data curation, T.W.; writing-original draft preparation, L.T.M. and Z.B.; writing-review and editing, L.T.M., F.B., Z.B., P.Y. and T.W.; visualization, L.T.M., P.Y., F.B. and T.W.; supervision, L.T.M. and T.W.; project administration, T.W.; funding acquisition, T.W. All authors have read and agreed to the published version of the manuscript.

Funding: This research received no external funding.

Institutional Review Board Statement: The study was approved by the Expert and Ethics Council of the Health Center of Slavonski Brod, Croatia, ID: 1433-1/020.

Informed Consent Statement: Not applicable.

Data Availability Statement: Not applicable.

Conflicts of Interest: The authors declare no conflict of interest.

\section{References}

1. Rea, I.M.; Gibson, D.S.; McGilligan, V.; McNerlan, S.E.; Alexander, H.D.; Ross, O.A. Age and age-related diseases: Role of inflammation triggers and cytokines. Front. Immunol. 2018, 9, 586. [CrossRef] [PubMed]

2. Bennett, J.M.; Reeves, G.; Billman, G.E.; Sturmberg, J.P. Inflammation-nature's way to efficiently respond to all types of challenges: Implications for understanding and managing "the epidemic" of chronic diseases. Front. Med. 2018, 5, 316. [CrossRef] [PubMed]

3. Franceschi, C.; Garagnani, P.; Morsiani, C.; Conte, M.; Santoro, A.; Grignolio, A.; Moni, D.; Capri, M.; Salvioloi, S. The continuum of aging and age-related diseases: Common mechanisms but different rates. Front. Med. 2018, 12, 61. [CrossRef] [PubMed]

4. Franceschi, C.; Garagnani, P.; Parini, P.; Giuliani, C.; Santoro, A. Inflammaging: A new immune-metabolic viewpoint for age-related diseases. Nat. Rev. Endocrinol. 2018, 14, 576-590. [CrossRef]

5. Pes, G.M.; Lio, D.; Carru, C.; Deiana, L.; Baggio, G.; Franceschi, C.; Ferrucci, L.; Oliveri, F.; Scola, L.; Crivello, A.; et al. Association between longevity and cytokine gene polymorphisms. A study in Sardinian centenarians. Aging Clin. Exp. Res. 2004, 16, 244-248. [CrossRef] [PubMed] 
6. Roden, M.; Shulman, G.I. The integrative biology of type 2 diabetes. Nature 2019, 576, 51-60. [CrossRef]

7. Cho, N.H.; Shaw, J.E.; Karuranga, S.; Huang, Y.; da Rocha Fernandes, J.D.; Ohlrogge, A.W.; Malanda, B. IDF diabetes atlas: Global estimates of diabetes prevalence for 2017 and projections for 2045. Diabetes Res. Clin. Pract. 2018, 138, 271-281. [CrossRef] [PubMed]

8. Virani, S.S.; Alonso, A.; Benjamin, E.J. Heart disease and stroke statistics-2020 update: A report from the American Heart Association. Circulation 2020, 141, 9. [CrossRef] [PubMed]

9. Cosentino, F.; Grant, P.J.; Aboyans, V.; Bailey, C.J.; Ceriello, A.; Delgado, V.; Federici, M.; Filippatos, G.; Grobbee, D.E.; Hansen, T.B.; et al. 2019 ESC Guidelines on diabetes, pre-diabetes, and cardiovascular diseases developed in collaboration with the EASD. Eur. Heart J. 2020, 41, 255-323. [CrossRef] [PubMed]

10. Mitchell, S.; Malanda, B.; Damasceno, A.; Eckel, R.H.; Gaita, D.; Kotseva, K.; Januzzi, J.L.; Mensah, G.; Plutzky, J.; Prystupiuk, M.; et al. A roadmap on the prevention of cardiovascular disease among people living with diabetes. Glob. Heart 2019, 14, 215-240. [CrossRef]

11. Das, S.R.; Everett, B.M.; Birtcher, K.K.; Brown, J.M.; Januzzi, J.L., Jr.; Kalyani, R.R.; Kosiborod, M.; Magwire, M.; Morris, P.B.; Neumiller, J.J.; et al. 2020 expert consensus decision pathway on novel therapies for cardiovascular risk reduction in patients with type 2 diabetes: A report of the American College of Cardiology Solution Set Oversight Committee. J. Am. Coll. Cardiol. 2020, 76, 1117-1145. [CrossRef] [PubMed]

12. Global Burden of Metabolic Risk Factors for Chronic Diseases Collaboration (BMI Mediated Effects); Lu, Y.; Hajifathalian, K.; Ezzati, M.; Woodward, M.; Rimm, E.B.; Danaei, G. Metabolic mediators of the effects of body-mass index, overweight, and obesity on coronary heart disease and stroke: A pooled analysis of 97 prospective cohorts with 1.8 million participants. Lancet 2014, 383, 970-983.

13. Abdelhafiz, A.H.; Brown, S.H.; Bello, A.; El Nahas, M. Chronic kidney disease in older people: Physiology, pathology or both? Nephron Clin. Pract. 2010, 116, c19-c24. [CrossRef] [PubMed]

14. Forman, D.E.; Maurer, M.S.; Boyd, C.; Brindis, R.; Salive, M.E.; Horne, F. Multimorbidity in older adults with cardiovascular disease. J. Am. Coll. Cardiol. 2018, 71, 2149-2161. [CrossRef]

15. Caruso, G.; Fresta, C.G.; Grasso, M.; Santangelo, R.; Lazzarino, G.; Lunte, S.M.; Caraci, F. Inflammation as the common biological link between depression and cardiovascular diseases: Can carnosine exert a protective role? Curr. Med. Chem. 2020, 27, 1782-1800. [CrossRef] [PubMed]

16. Trtica Majnarić, L.; Bosnić, Z.; Kurevija, T.; Wittlinger, T. Cardiovascular risk and aging: The need for a more comprehensive understanding. J. Geriatr. Cardiol. 2021, 18, 462-478. [PubMed]

17. Bekić, S.; Babič, F.; Pavlišková, V.; Paralič, J.; Wittlinger, T.; Majnarić, L.T. Clusters of physical frailty and cognitive impairment and their associated comorbidities in older primary care patients. Healthcare 2021, 9, 891. [CrossRef] [PubMed]

18. Babič, F.; Trtica Majnarić, L.; Bekić, S.; Holzinger, A. Machine learning for family doctors: A case of cluster analysis for studying aging associated comorbidities and frailty. In Machine Learning and Knowledge Extraction; Holzinger, A., Kieseberg, P., Tjoa, A., Weippl, E., Eds.; CD-MAKE: Canterbury, UK, 2019.

19. Fried, L.P.; Tangen, C.M.; Walston, J. Cardiovascular health study collaborative research group. Frailty in older adults: Evidence for a phenotype. J. Gerontol. A Biol. Sci. Med. Sci. 2001, 56, M146-M156. [CrossRef] [PubMed]

20. Volpato, S.; Guralnik, J.M.; Ferrucci, L.; Balfour, J.; Chaves, P.; Fried, L.P.; Harris, T.B. Cardiovascular disease, interleukin-6, and risk of mortality in older women: The women's health and aging study. Circulation 2001, 103, 947-953. [CrossRef]

21. Angkananard, T.; Anothaisintawee, T.; McEvoy, M.; Attia, J.; Thakkinstian, A. Neutrophil lymphocyte ratio and cardiovascular disease risk: A systematic review and meta-analysis. BioMed Res. Int. 2018, 2018, 2703518. [CrossRef] [PubMed]

22. Bupp, M.R.G. Sex, the aging immune system, and chronic disease. Cell. Immunol. 2015, 294, 102-110. [CrossRef] [PubMed]

23. Corriere, T.; Di Marca, S.; Cataudella, E.; Pulvirenti, A.; Alaimo, S.; Stancanelli, B.; Malatino, L. Neutrophil-to-lymphocyte ratio is a strong predictor of atherosclerotic carotid plaques in older adults. Nutr. Metab. Cardiovasc. Dis. 2018, 28, 23-27. [CrossRef] [PubMed]

24. Vaduganathan, M.; Ambrosy, A.P.; Greene, S.J.; Mentz, R.J.; Subacius, H.P.; Maggioni, A.P.; Swedberg, K.; Nodari, S.; Zannad, F.; Konstam, M.A.; et al. EVEREST trial investigators. Predictive value of low relative lymphocyte counts in patients hospitalized for heart failure with reduced ejection fraction: Insights from the EVEREST trial. Circ. Heart Fail. 2012, 5, 750-758. [CrossRef] [PubMed]

25. Tonyali, S.; Ceylan, C.; Yahsi, S.; Karakan, M.S. Does neutrophil to lymphocyte ratio demonstrate deterioration in renal function? Ren. Fail. 2018, 40, 209-212. [CrossRef] [PubMed]

26. Fairweather, D. Sex differences in inflammation during atherosclerosis. Clin. Med. Insights Cardiol. 2015, 8, 49-59. [CrossRef] [PubMed]

27. Lockhart, C.J.; Hamilton, P.K.; Quinn, C.E.; McVeigh, G.E. End-organ dysfunction and cardiovascular outcomes: The role of the microcirculation. Clin. Sci. 2009, 116, 175-190. [CrossRef]

28. Howard, R.; Scheiner, A.; Kanetsky, P.A.; Egan, K.M. Sociodemographic and lifestyle factors associated with the neutrophil-tolymphocyte ratio. Ann. Epidemiol. 2019, 38, 11-21. [CrossRef]

29. Fest, J.; Ruiter, R.; Ikram, M.A.; Voortman, T.; van Eijck, C.H.J.; Stricker, B.H. Reference values for white blood-cell-based inflammatory markers in the Rotterdam Study: A population-based prospective cohort study. Sci. Rep. 2018, 8, 10566. [CrossRef]

30. Iwakura, Y.; Ishigame, H. The IL-23/IL-17 axis in inflammation. J. Clin. Investig. 2006, 116, 1218-1222. [CrossRef] 
31. Trtica Majnarić, L.; Guljaš, S.; Bosnić, Z.; Šerić, V.; Wittlinger, T. Neutrophil-to-lymphocyte ratio as a cardiovascular risk marker may be less efficient in women than in men. Biomolecules 2021, 11, 528. [CrossRef] [PubMed]

32. Ma, J.; Li, Y.J.; Chen, X.; Kwan, T.; Chadban, S.J.; Wu, H. Interleukin 17A promotes diabetic kidney injury. Sci. Rep. 2019, 9, 2264. [CrossRef]

33. Su, Z.; Tao, X. Current understanding of IL-37 in human health and disease. Front. Immunol. 2021, 12, 696605. [CrossRef]

34. Li, T.; Li, H.; Li, W.; Chen, S.; Feng, T.; Jiao, W.; Wu, C.; Dong, J.; Li, Y.; Li, S.; et al. Interleukin-37 sensitize the elderly type 2 diabetic patients to insulin therapy through suppressing the gut microbiota dysbiosis. Mol. Immunol. 2019, 112, 322-329. [CrossRef] [PubMed]

35. Zhang, X.; Zhou, Y.; Fei, B. Interleukin 37 (IL-37) reduces high glucose-induced inflammation, oxidative stress, and apoptosis of podocytes by inhibiting the STAT3-cyclophilin a (CypA) signaling pathway. Med. Sci. Monit. 2020, 26, e922979-1-e922979-11. [CrossRef] [PubMed]

36. Krebs, C.F.; Turner, J.-E.; Riedel, J.-H.; Panzer, U. Tissue-specific therapy in immune-mediated kidney diseases: New ARGuments for targeting the IL-23/IL-17 axis. J. Clin. Investig. 2021, 131, e150588. [CrossRef]

37. López-Bautista, F.; Posadas-Sánchez, R.; Vázquez-Vázquez, C.; Fragoso, J.; Rodríguez-Pérez, J.; Vargas-Alarcón, G. IL-37 Gene and cholesterol metabolism: Association of polymorphisms with the presence of hypercholesterolemia and cardiovascular risk factors. The GEA Mexican study. Biomolecules 2020, 10, 1409. [CrossRef]

38. Calder, P.; Ahluwalia, N.; Albers, R.; Bosco, N.; Bourdet-Sicard, R.; Haller, D.; Holgate, S.; Jönsson, L.; Latulippe, M.; Marcos, A.; et al. A Consideration of biomarkers to be used for evaluation of inflammation in human nutritional studies. Br. J. Nutr. 2013, 109, S1-S34. [CrossRef]

39. Bellary, S.; Kyrou, I.; Brown, J.E.; Bailey, C.J. Type 2 diabetes mellitus in older adults: Clinical considerations and management. Nat. Rev. Endocrinol. 2021, 17, 534-548. [CrossRef]

40. Ljiljana, M.T.; Zvonimir, B.; Nikola, V.; Pınar, Y. Complexity and non-linearity of cardiovascular risk factors in older patients with multimorbidity and reduced renal function. J. Integr. Cardiol. 2020, 3, 1-11.

41. Zoungas, S.; Woodward, M.; Li, Q.; Cooper, M.E.; Hamet, P.; Harrap, S.; Heller, S.; Marre, M.; Patel, A.; Poulter, N.; et al. Impact of age, age at diagnosis and duration of diabetes on the risk of macrovascular and microvascular complications and death in type 2 diabetes. Diabetologia 2014, 57, 2465-2474. [CrossRef]

42. Majnarić-Trtica, L.; Vitale, B. Systems biology as a conceptual framework for research in family medicine; Use in predicting response to influenza vaccination. Prim. Health Care Res. Dev. 2011, 12, 310-321. [CrossRef] [PubMed]

43. Dezelic, G.; Kern, J.; Petrovecki, M.; Ilakovac, V.; Hercigonja-Szekeres, M. Medical informatics in Croatia-A historical survey. Acta Inform. Med. 2014, 22, 49-59. [CrossRef] [PubMed]

44. Šabanovic, Š.; Majnaric Trtica, L.; Babic, F.; Vadovsky, M.; Paralic, J.; Vcev, A.; Holzinger, A. Metabolic syndrome in hypertensive women in the age of menopause: A case study on data from general practice electronic health records. BMC Med. Inform. Decis. Mak. 2018, 18, 24. [CrossRef] [PubMed]

45. Weiss, G.; Ganz, T.; Goodnough, L.T. Anemia of inflammation. Blood 2019, 133, 40-50. [CrossRef] [PubMed]

46. Levey, A.S. A decade after the KDOQI CDK guidelines. Am. J. Kidney Dis. 2012, 60, 683-685. [CrossRef]

47. National Kidney Fundation. eGFR Calculator. Available online: https://www.kidney.org/professionals/kdoqi/gfr_calculator (accessed on 24 September 2021).

48. Barbesino, G. Thyroid function changes in the elderly and their relationship to cardiovascular health: A mini-review. Gerontology 2019, 65, 1-8. [CrossRef] [PubMed]

49. Bhat, T.; Tel, S.; Rija, J.; Bhat, H.; Raza, M. Neutrophil to lymphocyte ratio and cardiovascular diseases: A review. Expert Rev. Cardiovasc. Ther. 2013, 11, 55-59. [CrossRef] [PubMed]

50. Bralić Lang, V.; Bergman Marković, B. Prevalence of comorbidity in primary care patients with type 2 diabetes and its association with elevated HbA1c: A cross-sectional study in Croatia. Scand. J. Prim. Health Care 2016, 34, 66-72. [CrossRef] [PubMed]

51. Chang, Y.W.; Hung, L.C.; Chen, Y.C.; Wang, W.H.; Lin, C.Y.; Tzeng, H.H.; Suen, J.-L.; Chen, Y.-H. Insulin reduces inflammation by regulating the activation of the NLRP3 inflammasome. Front. Immunol. 2021, 11, 587229. [CrossRef] [PubMed]

52. Abdul-Ghani, M.; DeFronzo, R.A.; Del Prato, S.; Chilton, R.; Singh, R.; Ryder, R.E. Cardiovascular disease and Type 2 diabetes: Has the dawn of a new era arrived? Diabetes Care 2017, 40, 813-820. [CrossRef]

53. Landi, F.; Russo, A.; Liperoti, R.; Pahor, M.; Tosato, M.; Capoluongo, E.; Bernabei, R.; Onder, G. Midarm muscle circumference, physical performance and mortality: Results from the aging and longevity study in the Sirente geographic area ilSIRENTE study. Clin. Nutr. 2010, 29, 441-447. [CrossRef]

54. Nardi, R.; Scanelli, G.; Corrao, S.; Iori, I.; Mathieu, G.; Cataldi Amatrian, R. Co-morbidity does not reflect complexity in internal medicine patients. Eur. J. Intern. Med. 2007, 18, 359-368. [CrossRef]

55. Corrao, S.; Natoli, G.; Nobili, A.; Mannucci, P.M.; Pietrangelo, A.; Perticone, F.; Argano, C.; REPOSI Investigators. Comorbidity does not mean clinical complexity: Evidence from the RePoSI register. Intern. Emerg. Med. 2020, 15, 621-628. [CrossRef] [PubMed]

56. Whitty, C.J.M.; MacEwen, C.; Goddard, A.; Aldersonm, D.; Marshall, M.; Calderwood, C.; Atherton, F.; McBride, M.; Atherton, J.; Stokes-Lampard, H.; et al. Rising to the challenge of multimorbidity. BMJ 2020, 368, 16964. [CrossRef]

57. Plsek, P.E.; Greenhalgh, T. Complexity science: The challenge of complexity in health care. BMJ 2001, 323, 625-628. [CrossRef] [PubMed] 
58. Hall, M.; Frank, E.; Holmes, G.; Pfahringer, B.; Reutemann, P.; Witten, I.H. The WEKA data mining software: An update. ACM SIGKDD Explor. Newsl. 2009, 11, 10-18. [CrossRef]

59. WEKA. Weka 3: Data Mining Software in Java. Available online: http://www.cs.waikato.ac.nz/ml/weka (accessed on 21 August 2021).

60. Han, J.; Micheline, K. Data Mining: Concepts and Techniques; Morgan Kaufmann: Waltham, MA, USA, 2001.

61. Majnarić, L.T.; Babič, F.; O'Sullivan, S.; Holzinger, A. AI and big data in healthcare: Towards a more comprehensive research framework for multimorbidity. J. Clin. Med. 2021, 10, 766. [CrossRef] [PubMed]

62. Jain, A.K. Data clustering: 50 years beyond K-means. Pattern Recognit. Lett. 2009, 31, 651-666. [CrossRef]

63. Tan, P.; Steinbach, M.; Kumar, V. Introduction to Data Mining, Lecture Notes for Chapter 2; University of Minnesota: Minneapolis, MN, USA, 2004.

64. Bekić, S.; Babič, F.; Filipčić, I.; Majnarić, L. Clustering of mental and physical comorbidity and the risk of frailty in patients aged 60 years or more in primary care. Med. Sci. Monit. 2019, 25, 6820-6835. [CrossRef] [PubMed]

65. Nowakowska, M.; Zghebi, S.S.; Ashcroft, D.M.; Buchan, I.; Chew-Graham, C.; Holt, T.; Mallen, C.; Van Marwijk, H.; Peek, N.; Perera-Salazar, R.; et al. The comorbidity burden of type 2 diabetes mellitus: Patterns, clusters and predictions from a large English primary care cohort. BMC Med. 2019, 17, 145. [CrossRef]

66. Medzhitov, R. Inflammation 2010: New adventures of an old flame. Cell 2010, 140, 771-776. [CrossRef] [PubMed]

67. Chen, L.; Deng, H.; Cui, H.; Fang, J.; Zuo, Z.; Deng, J.; Li, Y.; Wang, X.; Zhao, L. Inflammatory responses and inflammationassociated diseases in organs. Oncotarget 2018, 9, 7204-7218. [CrossRef]

68. Majnarić, L.T.; Martinović, I.; Šabanović, Š.; Rudan, S.; Babič, F.; Wittlinger, T. The effect of hypertension duration and the age of onset on CV risk factors expression in perimenopausal women. Int. J. Hypertens. 2019, 2019, 9848125.

69. Nuzzo, A.; Rossi, R.; Modena, M.G. Hypertension alone or related to the metabolic syndrome in postmenopausal women. Expert Rev. Cardiovasc. Ther. 2010, 8, 1541-1548. [CrossRef] [PubMed]

70. Pennell, L.M.; Galligan, C.L.; Fish, E.N. Sex affects immunity. J. Autoimmun. 2012, 38, J282-J291. [CrossRef] [PubMed]

71. Rathod, K.S.; Kapil, V.; Velmurugan, S.; Khambata, R.S.; Siddique, U.; Khan, S.; Van Eijl, S.; Gee, L.C.; Bansal, J.; Pitrola, K.; et al. Accelerated resolution of inflammation underlies sex differences in inflammatory responses in humans. J. Clin. Investig. 2017, 127, 169-182. [CrossRef]

72. Mancini, A.; Di Segni, C.; Raimondo, S.; Olivieri, G.; Silvestrini, A.; Meucci, E.; Curro, D. Thyroid hormones, oxidative stress, and inflammation. Mediat. Inflamm. 2016, 2016, 6757154. [CrossRef]

73. Regitz-Zagrosek, V.; Lehmkuhl, E.; Weickert, M.O. Gender differences in the metabolic syndrome and their role for cardiovascular disease. Clinical research in cardiology. Off. J. Ger. Card. Soc. 2006, 95, 136-147.

74. Mikić, M.; Šestak, A.; Volarić, M.; Rudan, S.; Majnarić, L.T. Seasonality of the cardiac biomarker troponin in the Eastern Croatian population. J. Clin. Med. 2018, 7, 520. [CrossRef]

75. Walker, S.R.; Wagner, M.; Tangri, N. Chronic kidney disease, frailty and successful aging: A review. J. Ren. Nutr. 2014, 24, 364-370. [CrossRef] [PubMed]

76. Sinclair, A.J.; Rodriguez-Mañas, L. Diabetes and frailty: Two converging conditions? Can. J. Diabetes 2016, 40, 77-83. [CrossRef]

77. Kleipool, E.E.; Hoogendijk, E.O.; Trappenburg, M.C.; Handoko, M.L.; Huisman, M.; Peters, M. Frailty in older adults with cardiovascular disease: Cause, effect, or both? Aging Dis. 2018, 9, 489-497. [CrossRef]

78. Theofilis, P.; Vordoni, A.; Koukoulaki, M.; Vlachopanos, G.; Kalaitzidis, R.G. Dyslipidemia in chronic kidney disease: Contemporary concepts and future therapeutic perspectives. Am. J. Nephrol. 2021, 52, 693-701. [CrossRef] [PubMed]

79. Starr, K.N.P.; McDonald, S.R.; Bales, C.W. Obesity and physical frailty in older adults: A scoping review of intervention trial. J. Am. Med. Dir. Assoc. 2014, 15, 240-250. [CrossRef]

80. Nashar, K.; Egan, B.M. Relationship between chronic kidney disease and metabolic syndrome: Current perspectives. Diabetes Metab. Syndr. Obes. 2014, 7, 421-435. [CrossRef]

81. McAninch, E.A.; Bianco, A.C. Thyroid hormone signaling in energy homeostasis and energy metabolism. Ann. N. Y. Acad. Sci. 2014, 1311, 77-87. [CrossRef] [PubMed]

82. Sproston, N.R.; Ashworth, J.J. Role of C-reactive protein at sites of inflammation and infection. Front. Immunol. 2018, 9, 754. [CrossRef] [PubMed]

83. Corrao, S.; Argano, C.; Natoli, G.; Nobili, A.; Corazza, G.R.; Mannucci, P.M.; Perticone, F.; on behalf of REPOSI Investigators. Sex-differences in the pattern of comorbidities, functional independence, and mortality in elderly inpatients: Evidence from the RePoSI Register. J. Clin. Med. 2019, 8, 81. [CrossRef]

84. Samson, L.D.; Boots, A.M.H.; Ferreira, J.A. In-depth immune cellular profiling reveals sex-specific associations with frailty. Immun. Ageing 2020, 17, 20.

85. Frangogiannis, N. Transforming growth factor- $\beta$ in tissue fibrosis. J. Exp. Med. 2020, 217, e20190103. [CrossRef] [PubMed]

86. Franceschi, C.; Valensin, S.; Bonafè, M.; Paolisso, G.; Yashin, A.; Monti, D.; De Benedictis, G. The network and the remodeling theories of aging: Historical background and new perspectives. Exp. Gerontol. 2000, 35, 879-896. [CrossRef] 